Thomas zum Felde

\title{
Genetische Variation und Vererbung von Sinapinsäure-Verbindungen im Raps (Brassica napus L.)
}

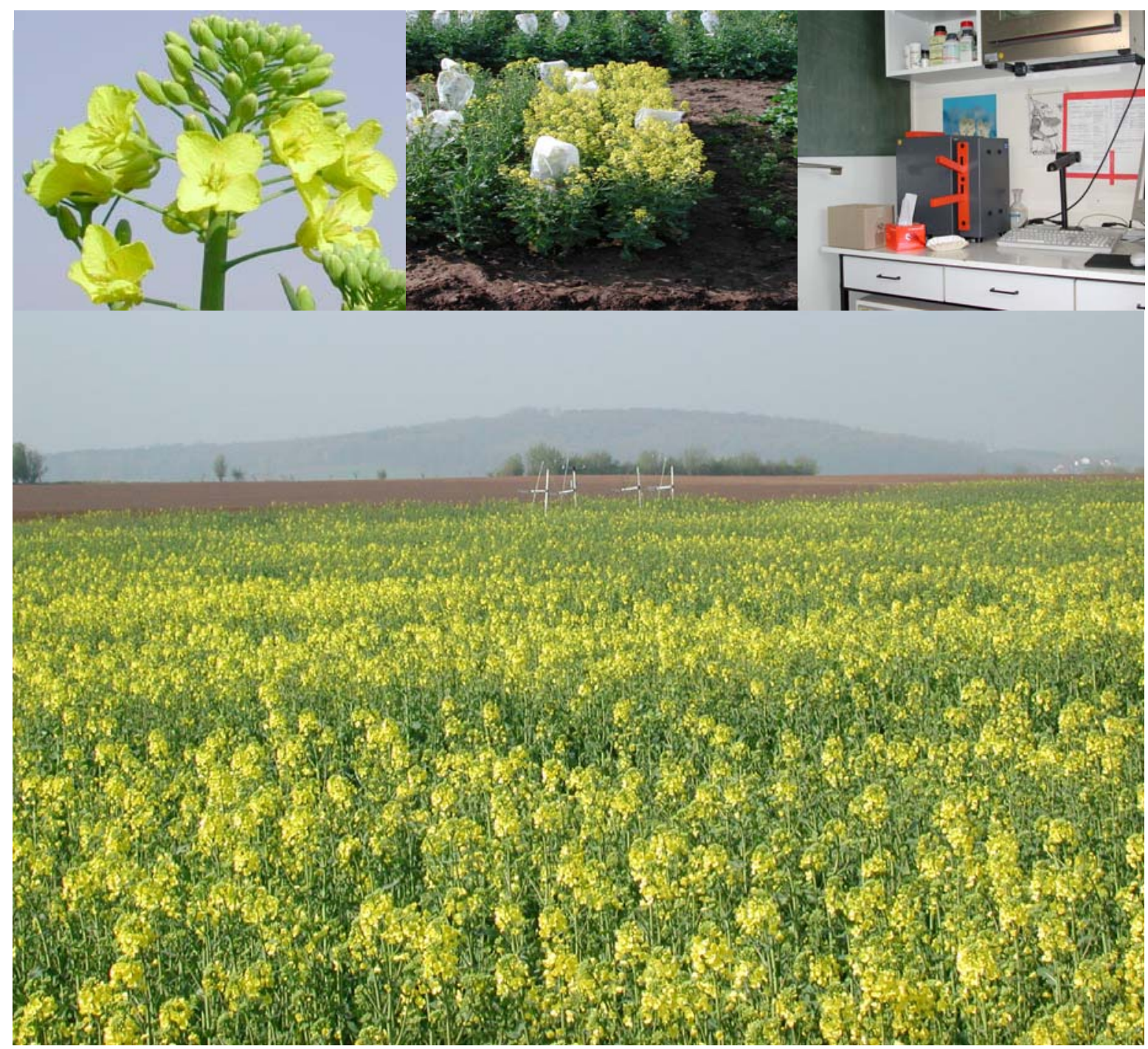




\title{
Genetische Variation und Vererbung von Sinapinsäure-Verbindungen im Raps (Brassica napus L.)
}

\author{
Dissertation \\ zur Erlangung des Doktorgrades \\ der Fakultät für Agrarwissenschaften \\ der Georg-August-Universität Göttingen
}

vorgelegt von

Thomas zum Felde aus Hamburg - Bergedorf

Göttingen, Oktober 2005 


\section{7}

1. Referent:

Prof. Dr. H.C. Becker

2. Korreferentin:

Prof. Dr. E. Pawelzik

Tag der mündlichen Prüfung: 09. November 2005 
„Wer hohe Türme bauen will, muß lange am Fundament verweilen." Anton Bruckner, österreichischer Komponist, 1824-1896 


\section{Inhaltsverzeichnis}

$1 \quad$ Einleitung und Zielsetzung

2 Literaturübersicht 3

2.1 Biosynthese der Sinapinsäureester in der Pflanze 3

2.2 Bedeutung der Sinapinsäureverbindungen für die Pflanze 5

2.3 Genetische Variation für den Gehalt an Sinapinsäureestern 5

3 Vergleich verschiedener Analyseverfahren für SinapinsäureVerbindungen und NIRS Kalibrationsentwicklung

$3.1 \quad$ Einleitung 6

3.2 Material und Methoden 6

$\begin{array}{lll}3.3 & \text { Ergebnisse und Diskussion } & 7\end{array}$

4 Untersuchung der genetischen Variation von SinapinsäureVerbindungen im Winterraps

$\begin{array}{lll}4.1 & \text { Einleitung } & 11\end{array}$

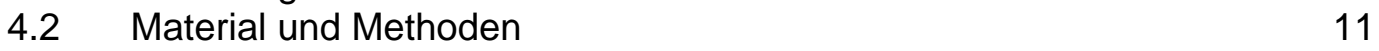

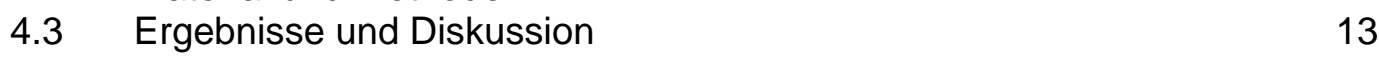

5 Genetische Variation für den Gehalt an Sinapinsäurestern im Raps und Entwicklung von NIRS Kalibrierungen

5.1 Zusammenfassung (ausführliche Darstellung siehe Manuskript I) 16

6 Genotyp x Umwelt Interaktionen, Heritabilitäten und Merkmalskorrelationen für den Gehalt an Sinapinsäureestern im Winterraps

6.1 Zusammenfassung (ausführliche Darstellung siehe Manuskript II)

7 Zusammenfassende Diskussion der züchterischen Möglichkeiten für die weitere Reduktion des Gehaltes an Phenolsäuren im Raps

$8 \quad$ Zusammenfassung 
Die folgenden Manuskripte in Anhang I und II sind Teil dieser Dissertation:

\section{Manuskript I}

Genetic variation for sinapate ester content in winter rapeseed (Brassica napus L.) and development of NIRS calibration equations

\section{Manuskript II}

Genotype x Environment interactions, heritability and trait correlations of sinapate ester content in winter rapeseed (Brassica napus L.) 


\section{$1 \quad$ Einleitung und Zielsetzung}

Raps (Brassica napus L.) stellt im europäischen Raum im Hinblick auf die Anbaufläche die wichtigste und weltweit die zweitwichtigste Ölsaat dar (FAO, 2004). Die weltweite Produktion betreffend wird der Raps nur von der Sojabohne und von der Ölpalme übertroffen (FAO 2004). Die enorme Ausweitung des Rapsanbaus innerhalb der vergangenen 25 Jahre geht auf Erfolge der klassischen Pflanzenzüchtung zurück. Die Verfügbarkeit der Gaschromatographie für die Analyse großer Probenzahlen erlaubte die Identifizierung von Genotypen mit einem im Samenöl deutlich reduzierten Gehalt an der für die menschliche Gesundheit als bedenklich identifizierten Erucasäure (22:1). Zunächst entwickelte '0+'-Sorten mit einem Erucasäuregehalt von unter 2\% wiesen nach wie vor hohe Gehalte an Senfölen (Glucosinolate) im Rapsextraktionsschrot auf, die dessen Verwertung in der Tierernährung verhinderten. Durch die Entwicklung photometrischer Tests (Thies 1982), HPLC- (Möller et al. 1985) und später von NahInfrarot-Spektroskopischer (NIRS)-Verfahren (Reinhardt 1992, Velasco und Becker 1998) konnten spontan aufgetretene Mutanten mit geringen Glucosinolatgehalten identifiziert und entsprechende Sorten gezüchtet werden. In Deutschland zugelassene Sorten enthalten heute weniger als $25 \mu \mathrm{mol}$ Glucosinolate $\mathrm{g}^{-1}$ Samen. Der so entstandene Doppel-Null ('00') Raps wurde im Jahr 1987 in der Bundesrepublik als Standardqualität eingeführt (Röbbelen 1999). Dies führte zu einem enormen Anstieg der Anbaufläche. In den letzten Jahren hat sich der Rapsanbau in Deutschland auf einem vergleichsweise hohem Niveau von mehr als 1,2 Mio ha stabilisiert (UFOP 2004).

Das Rapsöl steht heute mit an der Spitze der gesunden und ernährungsphysiologisch empfohlenen Speiseöle (Trautwein und Erbersdoppler 1998). Die züchterische Entwicklung von neuen Rapsformen mit spezifischen Ölqualitäten eröffnet weitere Absatzmöglichkeiten - sowohl im Nahrungsmittelbereich - als auch im „Non-Food“Bereich (Lühs et al. 2000, Möllers 2004). Dabei wird die Wettbewerbsfähigkeit von Raps nicht zuletzt auch von der Qualität des Rapsmehls als Koppelprodukt der Ölgewinnung bestimmt. Um die Verwertungsmöglichkeiten der Rapssaat insgesamt zu verbessern, gilt es nicht nur die Ölqualität gezielt zu beeinflussen, sondern auch den Gehalt an wertmindernden Inhaltsstoffen im Schrot zu vermindern. Im Rahmen des vom BMBF geförderten Leitprojektes „Napus 2000 - gesunde Lebensmittel aus transgener Rapssaat", wurden innerhalb eines größeren Forschungsverbundes konventionelle und gentechnische Ansätze zur Verbesserung der Rapssamenqualität verfolgt. Ein Schwerpunkt dieses Verbundvorhabens war es, die Proteinqualität des Rapses so zu verbessern, dass es als Alternative zum Sojaprotein für die Lebensmittelproduktion 
genutzt werden kann (Leckband 2002). Im Unterschied zur Sojabohne wurde der im Raps etwa 30 mal höhere Gehalt an Phenolsäureestern (Tab. 1) als eine mögliche Ursache für den vergleichsweise bitteren, adstringierenden Geschmack und die dunkle Farbe von Rapsproteinprodukten identifiziert (Kozlowska et al. 1990, Naczk et al. 1998, Shahidi und Naczk 1992). Darüber hinaus können Phenolsäuren und ihre Oxidationsprodukte Komplexe mit Aminosäuren und Proteinen bilden und dadurch den ernährungsphysiologischen Wert von Rapsproteinen reduzieren (Bell 1993, Griffith 1989). Sinapinsäureester machen dabei den Hauptanteil der im Raps vorkommenden phenolischen Verbindungen aus. Unter diesen dominiert im Samen mengenmäßig das Sinapoylcholin (Sinapin), gefolgt von Sinapoylglucose sowie weiterer in geringerer Menge vorkommender Sinapinsäureester, die noch nicht vollständig charakterisiert sind (Milkowski et al. 2004). Die freie Sinapinsäure selbst kommt ebenfalls nur in geringen Mengen vor (Milkowski et al. 2004). Nach unterschiedlichen Angaben variiert der Sinapinanteil am Gesamtgehalt zwischen 70\% (Bouchereau et al. 1991, Kolodziejczyk et al. 1999) und 80\% (Dabrowski and Sosulski 1984, Pokorny and Reblova 1995).

Tab. 1: Gesamtgehalt an Phenolsäuren im ölextrahierten Samenmehl einiger Ölpflanzen (aus Shahidi and Naczk 1992)

\begin{tabular}{lc}
\hline Mehl & $\begin{array}{c}\text { Phenolsäuregehalt } \\
(\mathrm{mg} / 100 \mathrm{~g})\end{array}$ \\
\hline Sojabohne & 23,4 \\
Baumwolle & 56,7 \\
Erdnuss & 63,6 \\
Raps & 639,9
\end{tabular}

Zur Reduzierung der im Rapssamen sehr hohen Phenolsäuregehalte bieten sich verschiedene züchterische Möglichkeiten an. Die vorhandene genetische Variation kann zunächst erfasst und dann können Genotypen mit einem geringen Gehalt an Phenolsäuren miteinander gekreuzt werden, um in den Nachkommenschaften Genotypen mit einem weiter reduzierten Gehalt zu identifizieren. Über die vorhandene genetische Variation hinausgehende Variation kann mit Hilfe der Mutationszüchtung und der Gentechnologie erzeugt werden. In jedem Fall wird für die Verfolgung des Zuchtzieles 'niedriger Phenolsäuregehalt' im Rahmen von Zuchtprogrammen eine effiziente, preisgünstige und möglichst zerstörungsfreie Nachweismethode benötigt. 
Das Ziel der vorliegenden Arbeit war es, mit Hilfe von HPLC-Analysen die genetische Variation für den Gehalt und die Zusammensetzung an Sinapinsäureestern in Samen eines großen Sortimentes unterschiedlicher Rapsgenotypen zu untersuchen. Genotypen mit einem geringen Gehalt sollten identifiziert und nach Anbau dieser Genotypen im Feldversuch die Gehalte verifiziert werden. Für den routinemäßigen Einsatz in der Pflanzenzüchtung sollten weiterhin NIRS-Kalibrierungen für die Schätzung des Gesamtgehaltes an Sinapinsäureverbindungen sowie für die einzelnen Komponenten entwickelt werden. Letztendlich sollten im Rahmen von mehrortigen Feldversuchen mit spaltenden doppelthaploiden Rapspopulationen die Genotyp x Umwelt Interaktionen untersucht, die Heritabilitäten geschätzt und mögliche Korrelationen zu anderen qualitätsbestimmenden Inhaltsstoffen im Raps bestimmt werden.

\section{Literaturübersicht}

Veresterte Phenolsäuren stellen im Rapssamen die vorherrschende Fraktion der Phenolsäuren dar; sie machen etwa $80 \%$ des Gesamtgehaltes an Phenolsäuren aus (Naczk et al. 1998). Daneben kommen in geringerer Konzentration freie Phenolsäuren und unlöslich gebundene Phenolsäuren vor. Sinapinsäure macht dabei sowohl unter den veresterten als auch unter den freien Phenolsäuren mit 70-85\% den größten Anteil aus. Neben der Sinapinsäure wurden p-Hydroxybenzoesäure, Vanillinsäure, Gentisinsäure, Protokatechusäure, Syringinsäure, p-Coumarsäure, Ferulasäure, Kaffeesäure und Chlorogensäure in freier bzw. veresterter Form nachgewiesen (Naczk et al. 1998).

\subsection{Biosynthese der Sinapinsäureester in der Pflanze}

Die Sinapinsäure entsteht als ein Produkt der Zimtsäurebiosynthese. Ausgehend von den Aminosäuren Tyrosin und Phenylalanin entsteht durch oxidative Decarboxylierung Zimtsäure bzw. p-Coumarsäure. Von der Zimtsäure verläuft die weitere Biosynthese über Kaffeesäure, Ferulasäure und 5-Hydroxi-Ferulasäure hin zur Sinapinsäure. Die im Raps vorhandenen Sinapinsäureester unterliegen nach Strack et al. (1983) während der Entwicklung der Pflanze verschiedenen Umwandlungsprozessen. Der Biosyntheseweg der wichtigen Sinapinsäureester in Samen und Sämlingen des Raps sowie die wichtigsten involvierten Enzyme sind in Abb. 1 dargestellt. 


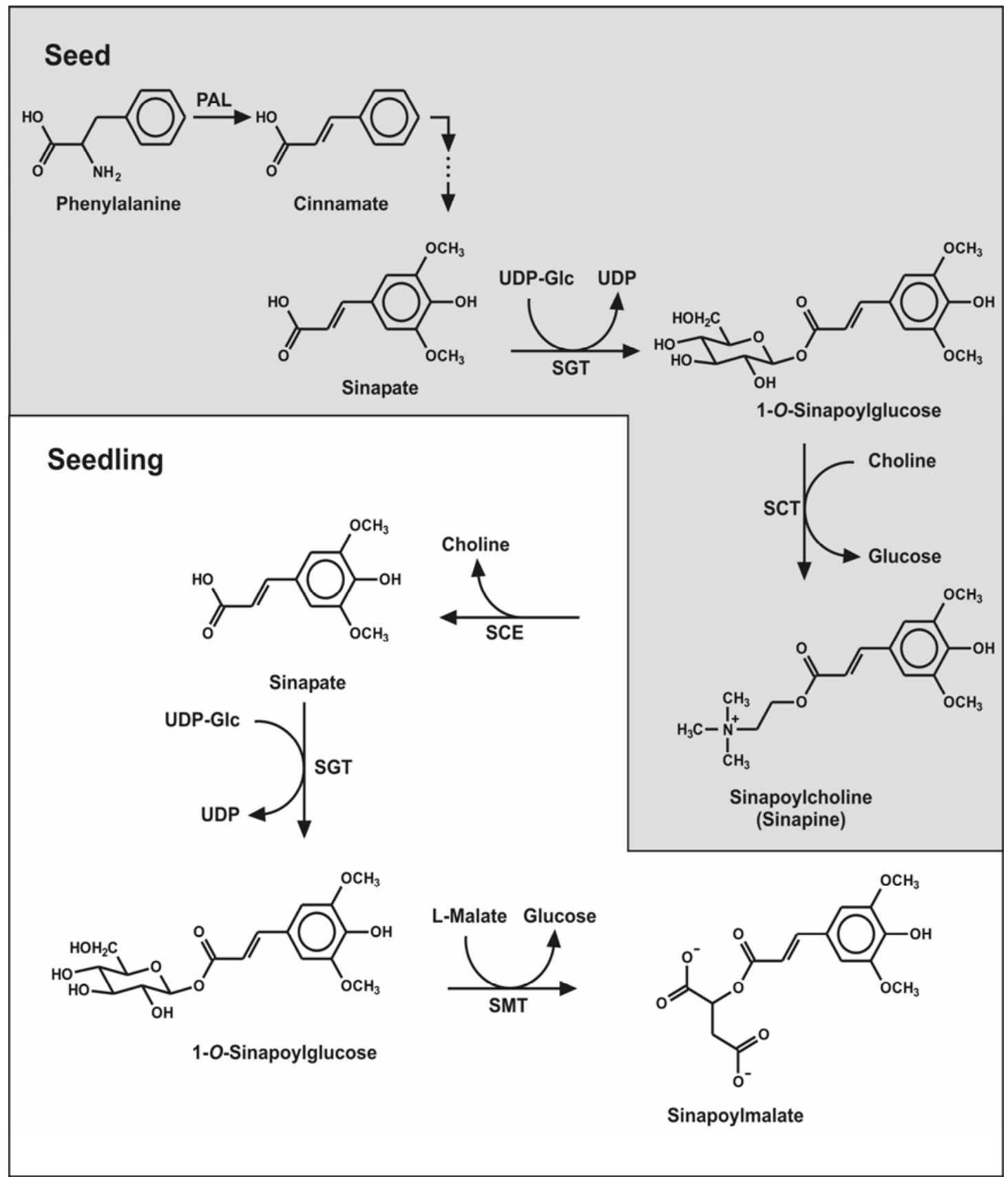

Abb. 1: Biosyntheseweg der wichtigen Sinapinsäureester in Samen und Sämlingen des Raps (nach Milkowski et al. 2004 und Hüsken et al. 2005b). Die involvierten Enzyme sind: UDP-glucose (UDP-GIc):sinapate glucosyltransferase (SGT; EC 2.4.1.120), 1-Osinapoyl- $\beta$-glucose:choline sinapoyltransferase (SCT; EC 2.3.1.91), sinapoylcholine esterase (SCE; EC 3.1.1.49), und 1-O-sinapoyl- $\beta$-glucose:malate sinapoyltransferase (SMT; EC 2.3.1.92). 
Das Enzym Sinapinsäure-Glucosyltransferase (SGT) katalysiert im Samen die Bildung von Sinapoylglucose aus Sinapinsäure und UDP-Glucose. Die Sinapoylglucose ist nur ein Zwischenprodukt; sie dient als Sinapinsäure-Donor für die Bildung von Sinapin bzw. Sinapoylmalat. Das Sinapin wird aus 1-0-Sinapoyl-ß-D-Glucose und Cholin gebildet. Diese Reaktion wird durch das Enzym Sinapoyl-Cholintransferase (SCT) beschleunigt. Die Sinapoylmalat-Bildung wird durch das spezifische Enzym Sinapoyl-L-Malattranferase (SMT) katalysiert (Strack et al. 1983, Chapple et al. 1992). Sinapoylglucose und Sinapin werden spezifisch im Samen synthetisiert, während in den vegetativen Pflanzenteilen hauptsächlich Sinapoylmalat gebildet wird (Strack et al. 1983, Lorenzen et al. 1996).

\subsection{Bedeutung der Sinapinsäure-Verbindungen für die Pflanze}

In Arabidopsis thaliana wurde für Sinapoylmalat und andere Sinapinsäureester in den vegetativen Pflanzenteilen eine Bedeutung als UV-Schutz nachgewiesen (Milkowski et al. 2004). Für das spezifisch in den Samen synthetisierte Sinapin ist die Bedeutung noch unklar. Es wird jedoch vermutet, dass Sinapin in den Samen als Sinapinsäure- und Cholinspeicher für die nach Keimung einsetzende Lignin- und Membranlipidbiosynthese fungiert (Strack 1981). Bei Arabidopsis wurden Mutanten identifiziert, die einen genetischen Block vor der Sinapinsäure (Ferulasäure-5-Hydroxilase) aufweisen und daher keine Sinapinsäureester bilden können. Eine Beeinträchtigung der Vitalität dieser Pflanzen konnte nicht beobachtet werden (Chapple et al. 1992). Auf Grund der bitteren und adstringierenden Eigenschaften der Phenolsäuren und ihrer Ester kann eine fraßhemmende Wirkung oder eine antifungale Wirkung nicht ausgeschlossen werden.

\subsection{Genetische Variation für den Gehalt an Sinapinsäureestern}

Umfangreiche Untersuchungen zum Sinapinsäureestergehalt verschiedener BrassicaArten und Herkünfte zeigen eine z.T. erhebliche Variabilität für dieses Merkmal (Kozlowska et al. 1990, Bouchereau et al. 1991, Kräling et al. 1991). Die Gehalte können 1-2\% des Samens ausmachen. In neueren Untersuchungen konnten Velasco und Möllers (1998) unter mehr als 1300 Brassica napus-Samenproben Phänotypen mit Sinapingehalten von 5,0 bis $17,7 \mathrm{mg} / \mathrm{g}$ Samen identifizieren. Die nachgewiesene Variabilität lässt eine Selektion auf niedrigen Sinapingehalt möglich erscheinen. 


\section{Vergleich verschiedener Analyseverfahren für Sinapinsäure- Verbindungen und NIRS Kalibrationsentwicklung}

\subsection{Einleitung}

Für den Nachweis von Phenolsäuren und ihrer Ester sind in der Literatur verschiedene Verfahren beschrieben worden. Häufig angewendet wurde der von Thies (1991) beschriebene photometrische Test. Vorteil dieses Tests ist, dass er eine relative schnelle Abschätzung des Phenolsäureestergehaltes erlaubt. Nachteilig dagegen ist, dass die Samen zunächst gemahlen werden müssen, der Test relativ ungenau ist und die für bestimmte Fragestellungen wichtige getrennte Bestimmung der einzelnen Sinapinsäureester nicht möglich ist. Für die exakte Bestimmung der Sinapinsäure und ihrer Ester bietet sich die RP-HPLC an (Milkowski et al. 2004), die allerdings vergleichsweise langsam und teuer ist. Als sehr schnelle, zerstörungsfreie und damit preiswerte Methode für die hinreichend genaue Bestimmung vieler Qualitätsmerkmale hat sich die Nah-Infrarot-Reflektions Spektroskopie (NIRS) erwiesen. Auch für den Phenolsäuregehalt wurde basierend auf dem von Thies (1991) beschriebenen photometrischen Test eine NIRS-Kalibrierung entwickelt (Velasco et al. 1998).

Zu Beginn der vorliegenden Arbeit standen sowohl der photometrische Test (Thies 1991) als auch die von Velasco et al. (1998) entwickelte NIRS-Kalibrierung für die Bestimmung des Gehaltes an Sinapinsäureestern zur Verfügung. Darüber hinaus stand das am Leibniz Institut für Pflanzenbiochemie in Halle entwickelte HPLC-Verfahren (Milkowski et al. 2004) sowie das darauf basierende eigene HPLC-Verfahren zur Verfügung. Ziel war es zunächst die unterschiedlichen Verfahren im Hinblick auf die Bestimmung der Sinapinsäureester im Raps zu vergleichen. Anschließend sollten auf HPLC-Ergebnissen basierende NIRS-Kalibrierungen für die einzelnen Sinapinsäureverbindungen und für den Gesamtgehalt entwickelt und validiert werden.

\subsection{Material und Methoden}

Für den Vergleich der Analysenverfahren wurden Samenproben verschiedener Winterraps-Genotypen verwendet (siehe Kapitel 4.2). Der photometrische Schnelltest wurde nach Thies (1991) und Hüsken (2001) durchgeführt. Die am IPB in Halle durchgeführte HPLC-Methode ist im Manuskript I und die in Göttingen durchgeführte HPLC-Methode ist im Manuskript II beschrieben. Sinapinsäure, Sinapin und Sinapoylglucose wurden mit Hilfe entsprechender Standards identifiziert und 
quantifiziert. Weitere sinapinsäurehaltige Verbindungen wurden am IPB in Halle anhand ihrer bei 240nm und 330nm charakteristischen Absorptionsmaxima mit Hilfe eines PDADetektors identifiziert und als Sinapinsäureäquivalente quantifiziert. Im weiteren werden diese Verbindungen zusammen als 'andere SE' bezeichnet. In Göttingen wurden diese Verbindungen durch einen Vergleich eigener Chromatogramme mit denen aus Halle identifiziert. Die NIRS-Kalibrationsentwicklung wurde wie im Manuskript I beschrieben durchgeführt. Bei der Auswahl des Materials für die Kalibrierung wurde neben der Variation im Gehalt an Sinapinsäurestern auch auf die Herkunft des Materials und auf die Umwelt (Erntejahr und -ort) geachtet (siehe Kapitel 4.2).

\subsection{Ergebnisse und Diskussion}

Bei dem Vergleich der mit Hilfe der NIRS-Kalibrierung von Velasco et al. (1998) und dem der Kalibrierung zugrunde liegenden photometrischen Schnelltest (Thies 1991) ermittelten Werten konnte eine Korrelation von $r=0,68(n=125)$ festgestellt werden. Beim Vergleich der mittels NIRS und HPLC (IPB Halle; $n=184$ ) erzielten Analysenergebnisse für den Gesamtgehalt ergab sich eine Korrelation von $r=0,59$. Dieses nicht ganz zufrieden stellende Ergebnis kann möglicherweise durch eine nicht ausreichende Genauigkeit des photometrischen Schnelltests und an der Verwendung von Samenproben liegen, für die die NIRS Kalibrierung von Velasco et al. (1998) keine hinreichend genaue Schätzung der Sinapingehalte lieferte. Auch ein Vergleich der mittels HPLC (IPB Halle, $n=125$ ) und mittels photometrischem Schnelltest erzielten Ergebnisse zeigte nur eine unbefriedigende Korrelation von $r=0,51$. Neben den oben angeführten Gründen kann dieses auch auf den zusätzlichen Nachweis weiterer Phenolsäuren und deren Ester im Raps durch den Schnelltest zurückzuführen sein. Die mittels HPLC in Halle und in Göttingen erzielten Ergebnisse zeigten dagegen eine gute Übereinstimmung für Sinapoylglucose $\left(R^{2}=0,97\right)$, Sinapin $\left(R^{2}=0,97\right)$ und für die anderen $\mathrm{SE}\left(\mathrm{R}^{2}=0,87\right)$. Das Bestimmtheitsmaß für den Gesamtgehalt betrug $R^{2}=0,94$ (Abb. 2). 


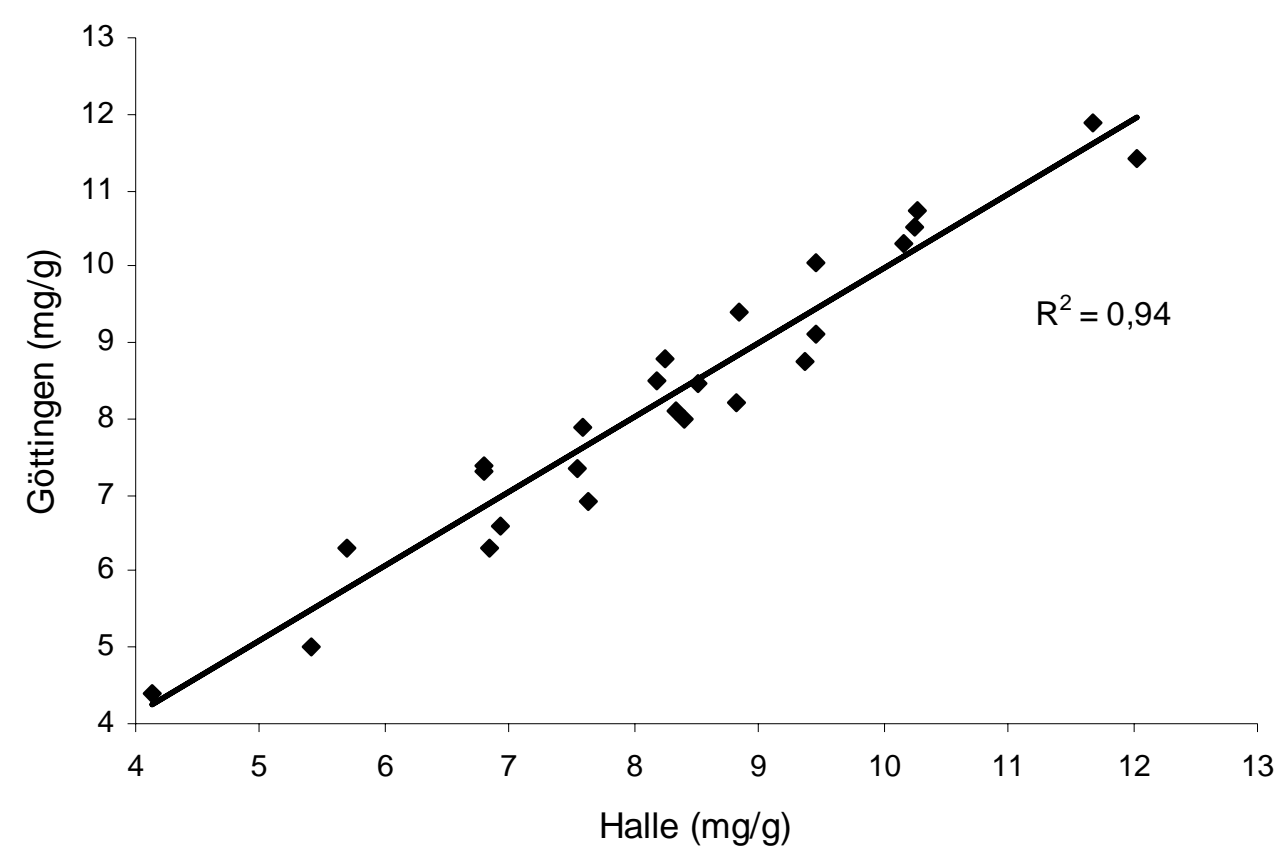

Abb. 2: Vergleich der in Göttingen und in Halle erzielten HPLC-Analysenergebnisse für den Gesamtgehalt an Sinapinsäureestern $(n=27)$

Da sowohl der photometrische Schnelltest als auch die NIRS-Kalibrierung von Velasco et al. (1998) keine ausreichend genaue Bestimmung des Gesamtgehaltes an Sinapinsäureestern erlaubte, wurden basierend auf der beim Projektpartner am IPB in Halle etablierten HPLC-Analytik neue NIRS-Kalibrierungen für die sinapinsäurehaltigen Verbindungen entwickelt. Zwar zeigten die am IPB in Halle und die in Göttingen mittels HPLC erzielten Ergebnisse eine gute Übereinstimmung, dennoch wurden, um zusätzliche Fehlerquellen auszuschließen, alle die für die NIRS-Kalibrierung verwendeten Samenproben $(n=549)$ in Halle analysiert. Die NIRS-Kalibrationsstatistik ist im Manuskript I in Tab. 1 dargestellt. Die für Kalibrierungen ermittelten statistischen Werte sind nicht so gut, wie die von Velasco et al. (1998) beschriebenen. Dies kann an dem unterschiedlichen Probensatz und/oder an einer unterschiedlichen Handhabung bei der Eliminierung von Ausreißern liegen. Auch zeigen die oben dargestellten Ergebnisse des Methodenvergleichs NIRS (Velasco et al. 1998) und HPLC Halle unter Verwendung eines neuen Probensatzes nur eine mittelmäßige Übereinstimmung. Im Unterschied zu der von Velasco et al. (1998) publizierten NIRS-Kalibration erlauben die im Rahmen dieser Arbeit entwickelten Kalibrierungen eine ausreichend genaue Schätzung der Gehalte der einzelnen Komponenten Sinapin, Sinapoylglucose und der anderen SE, um 
Genotypen mit niedrigen Gehalten identifizieren zu können. Die nach Kreuzvalidierung erhaltenen geringeren Bestimmtheitsmaße für den Anteil der durch die Kalibrierung erklärten Varianz der Referenzwerte (HPLC) deuten an, dass die Kalibrierungen durch die Aufnahme weiterer informativer Proben verbessert werden kann. Die Einbeziehung von Samenproben aus transgenen Versuchen (Nair et al. 2000, Hüsken et al. 2005a,b) mit erheblich reduzierten Gehalten an Sinapinsäureestern würde die Variation im Kalibrationsprobensatz erheblich erweitern.

Für die NIRS-Kalibrierungen wurden 549 genotypisch divergente Samenproben aus den Erntejahren 1997 bis 2002 verwendet. Um zu überprüfen, inwiefern die Kalibrierungen geeignet sind, die Gehalte an Sinapinsäureverbindungen von Proben aus Erntejahren, die nicht in der Kalibration repräsentiert sind, richtig zu schätzen, wurden die 58 Proben aus dem Erntejahr 1999 aus der Kalibrationsdatei entfernt und als externer Validationsprobensatz verwendet. Die in Tabelle 2 dargestellten Ergebnisse zeigen für Sinapin unerwartet einen, im Vergleich zum Standardfehler der Kalibrierung nach Kreuzvalidierung (SECV; siehe Tab. 1 in Manuskript I) reduzierten SEP(C), einen erwartungsgemäß leicht erhöhten SEP(C)-Wert für Sinapoylglucose und einen deutlichen erhöhten SEP(C) für den Gesamtgehalt.

Tab. 2: Externe Validierungsstatistik ( $n=58$ Samenproben aus dem Erntejahr 1999)

\begin{tabular}{lccccc}
\hline & $\begin{array}{c}\mathrm{SEP}^{\mathrm{a}} \\
\mathrm{mg} / \mathrm{g}\end{array}$ & Bias & $\begin{array}{c}\mathrm{SEP}(\mathrm{C})^{\mathrm{b}} \\
\mathrm{mg} / \mathrm{g}\end{array}$ & slope & $\mathrm{R}^{2} \mathrm{v}$ \\
\hline Sinapin & 0,53 & $-0,04$ & 0,53 & 0,95 & 0,85 \\
Sinapoylglucose & 0,84 & 0,34 & 0,77 & 1,23 & 0,75 \\
Andere SE $^{1}$ & n.b. & n.b. & n.b. & n.b. & n.b. \\
Gesamt SE $^{1}$ & 1,13 & $-0,14$ & 1,13 & 1,13 & 0,62 \\
\hline
\end{tabular}

${ }^{1}$ berechnet als Sinapinsäure, ${ }^{a}$ SEP $=$ Standardfehler der Vorhersage, ${ }^{b}$ SEP $(C)=$ Standardfehler der Vorhersage, korrigiert um den systematischen Fehler (Bias), $\mathrm{R}^{2} \mathrm{v}=$ Bestimmtheitsmaß der Validierung, n.b. nicht berechnet

Entsprechend wurden für das Bestimmtheitsmaß der Validierung $\left(R^{2} v\right)$ ähnliche Werte für Sinapin und Sinapoylglucose und ein mit $R^{2} v=0,62$ vergleichsweise deutlich reduzierter Wert für den Gesamtgehalt $\left(R^{2}{ }_{c v}=0,80\right.$; siehe Tab. 1 in Manuskript I) gefunden. Das für den Gesamtgehalt gefundene Bestimmtheitsmaß der Validierung von $R^{2} v=0,62$ entspricht in etwa dem oben dargestellten Ergebnis der Validierung NIRS (Velasco et al. 1998) versus photometrischer Test, bei dem ein Bestimmtheitsmaß von 0,68 erhalten wurde. Auch der Vergleich der HPLC- (IPB Halle) und NIRS-Ergebnisse von $n=27$ 
Ernteproben aus dem Jahr 2004 ergab für den Gesamtgehalt an sinapinsäurehaltigen Verbindungen ein Bestimmtheitsmaß von 0,60 (Möllers, pers.Mitteilung). Diese Ergebnisse zeigen, dass bei Anwendung der NIRS-Kalibrierungen auf neue Probensätze teilweise eine Überprüfung der ermittelten Gehalte mittels Referenzmethode stattfinden sollte. Bei der im Rahmen der vorliegenden Arbeit auf Grund von Ergebnissen mehrortiger Feldversuche nachgewiesene Variation im Gesamtgehalt an SEVerbindungen von 4,9 bis 9,2 mg Sinapinsäure $\mathrm{g}^{-1}$ Samen (siehe Tab. 4, Manuskript I), ist die Güte der Kalibrierungen ausreichend, um Genotypen mit einem geringen Gehalt an sinapinsäurehaltigen Verbindungen zu identifizieren. Dennoch sollten, wie bereits oben diskutiert, die Kalibrationsdateien mit spektral und im Hinblick auf eine erweiterte Variation informativen Probenspektren ergänzt werden. Damit kann mittelfristig eine weitere Verbesserung der Vorhersagegenauigkeit der Kalibrierungen erreicht werden. 


\section{$4 \quad$ Untersuchung der genetischen Variation von Sinapinsäure-Verbindungen im Winterraps}

\subsection{Einleitung}

Das Vorhandensein von genetischer Variation für ein Merkmal ist eine wichtige Voraussetzung, um eine züchterische Verbesserung zu erzielen. Zu Beginn der vorliegenden Arbeit lagen bereits erste Erkenntnisse über das Vorhandensein von phänotypischer Variation für den Gesamtgehalt an Sinapinsäureestern vor (Kräling et al. 1991, Bouchereau et al. 1991, Velasco und Möllers 1998). Ziel der vorliegenden Arbeit war es, ein möglichst großes, genetisch divergentes Winterraps-Sortiment bestehend aus Sorten, Zuchtlinien, Genbank-Material und resynthetisiertem Raps auf seine phänotypische Variation im Gesamtgehalt und in der Zusammensetzung an sinapinsäurehaltigen Verbindungen zu untersuchen. Genotypen mit vergleichsweise niedrigen und hohen Gehalten sollten dann im Rahmen von mehrortigen Feldversuchen geprüft werden, um genotypische Unterschiede festzustellen.

\subsection{Material und Methoden}

Für die Untersuchung der genotypischen Variation und für die Entwicklung der NIRSKalibrierungen wurden Ernteproben der Jahre 1997 bis 2002 verwendet. Für die Auswahl von interessantem Material mit Hilfe der NIRS-Kalibrierung von Velasco et al. (1998) sowie eigener vorläufiger NIRS-Kalibrierungen standen aus dem Institut für Pflanzenbau und Pflanzenzüchtung NIRS-Spektren zur Verfügung. Insgesamt wurden 2549 Spektren von DH-Populationen (DH Mansholts x DH Samourai, DH Mansholts' x Express, Apex x Mohican, Hoch-Ölsäure-Material, DH-Linien der Firma Semundo); von Winterraps-Material der Genbank IPK Gatersleben, Aussenstelle Malchow, nach Anbau in Göttingen; und von resynthetisierten Rapsen ausgewertet. Das für die Kalibration verwendete Material ist in Tab. 3 dargestellt. Darüber hinaus wurden von der Norddeutschen Pflanzenzucht Hans-Georg Lembke KG (NPZ), Hohenlieth, und der Deutschen Saatveredlung (DSV), Lippstadt, NIRS-Spektren von ihrem Zuchtmaterial der Ernte 2001 zur Verfügung gestellt. Nach Auswertung der Spektren mit Hilfe der NIRSKalibrierungen wurde Saatgut von den Genotypen mit extremen Gehalten angefordert. Diese wurden während der Jahre 2001 bis 2002 im Zuchtgarten des Versuchsguts Reinshof, Universität Göttingen, in Doppelreihen geprüft. Nach Selbstung geerntetes Saatgut wurde mittels HPLC bzw. NIRS untersucht. 
Tab. 3: Übersicht über das für die Entwicklung der NIRS-Kalibrierungen verwendete Material $(n=549)$

\begin{tabular}{lcc}
\hline Herkunft & Erntejahr & Anzahl \\
\hline Norddeutsche Pflanzenzucht Hans-Georg & 1999 & 24 \\
Lembke KG (NPZ), Hohenlieth & 2001 & 15 \\
& 2002 & 88
\end{tabular}

Deutsche Saatveredlung (DSV), Lippstadt

1999 14

2002

79

Prof. Jan Oleijniczak, Polnische Akademie der 1999 4

Wissenschaft, Polen (Mutationsversuch)

2000 33

Union zur Förderung von Oel- und 2000 40

Proteinpflanzen (UFOP), Sortenversuche

2001 10

Göttingen, doppelthaploide Linien aus der Kreuzung DH Mansholts x Express

1999 5

2000 5

2001 10

Göttingen, Resynthesen

1996 5

1997 18

1998 12

2000

Genbank-Material (IPK Gatersleben, Außenstelle Malchow, angebaut in Göttingen)

Göttingen, Zuchtmaterial mit einem hohen 1999 11

Ölsäuregehalt

2001 14

Göttingen, Nachbau ausgewählten Materials 


\subsection{Ergebnisse und Diskussion}

Der aus dem zur Verfügung stehenden Material für die NIRS-Kalibrierung ausgewählte Probensatz zeigte nach HPLC-Analyse eine erhebliche phänotypische Variation für den Gehalt an einzelnen Sinapinsäureverbindungen (Tab. 1 und Abb. 1; Manuskript I). Nach Erstellung erster zufriedenstellender NIRS-Kalibrierungen und Auswertung weiterer in Göttingen vorhandener Spektren sowie der von der NPZ und DSV zur Verfügung gestellten Spektren konnte eine ähnlich große Variation festgestellt werden (Tab. 3; Manuskript I). Dabei zeigten die Ergebnisse für das Göttinger Material eine größere Häufigkeit von Genotypen mit hohen und niedrigen Gehalten, was möglicherweise auf den größeren Anteil an nicht adaptiertem Material (Resynthesen, Genbank-Material, etc.) zurückzuführen sein kann. In Abb. 3 sind die Häufigkeitsverteilungen beispielhaft für Sinapoylglucose dargestellt.

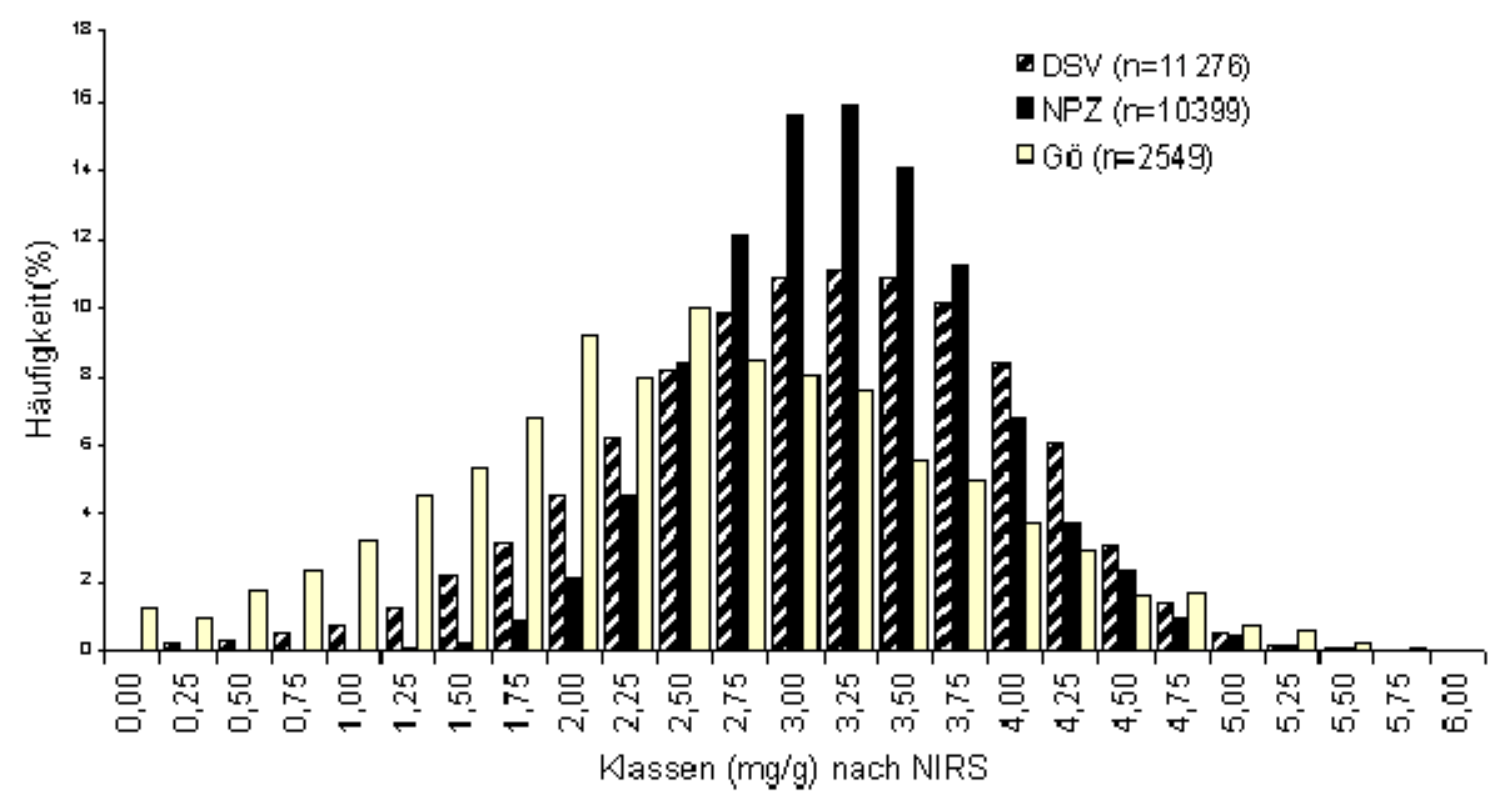

Abb. 3: Häufigkeitsverteilung der mittels NIRS anhand zur Verfügung gestellter Spektren von Ernteproben ermittelten Gehalte an Sinapoylglucose. Die von der NPZ und der DSV zur Verfügung gestellten Spektren der Ernte 2001 wurden auf das Göttinger Gerät standardisiert.

In einem mit ausgewähltem Material in zwei Jahren an zwei Orten mit 2 Wiederholungen durchgeführten Versuch, konnte mittels HPLC-Analyse eine genotypische Variation für den Gesamtgehalt an Sinapinsäureestern von 4,9 bis 9,2 mg Sinapinsäure $\mathrm{g}^{-1}$ Samen festgestellt werden (Tab. 4; Manuskript I). Genotypen mit einem geringen Gesamtgehalt 
enthielten 30-40\% weniger Sinapinsäureester als mitgeprüfte Vergleichssorten. In diesem Versuch fiel die, aus der alten Landsorte Mansholts' Hamburger Raps über Mikrosporenkultur gewonnene Linie DH Mansholts' durch besonders geringe Gesamtgehalte auf. In nachstehender Tabelle 4 sind die im Laufe der vorliegenden Arbeit identifizierten Genotypen mit besonders niedrigen und besonders hohen Gehalten aufgeführt. Die niedrigen Gesamtgehalte von DH Mansholts' haben sich auch in unabhängig von dem oben genannten Feldversuch durchgeführten Versuchen bestätigt. Noch geringere Gesamtgehalte konnten in doppelthaploiden Linien aus der Kreuzung DH Mansholts' x Express und DH Mansholts' x DH Samourai identifiziert werden. Auch die nach Mutagenese aus der polnischen Sorte Skrzeszowicki erhaltene Linie Skz. 33-4 zeichnete sich durch niedrige Gesamtgehalte aus. Die Linien mit den höchsten Gehalten enthielten bis zu $10 \mathrm{mg}$ Sinapinsäure $\mathrm{g}^{-1}$ Samen. Die Sorten Express, Mohican und Skrzeszowicki wiesen Gehalte um die $8 \mathrm{mg}$ Sinapinsäure $\mathrm{g}^{-1}$ Samen auf. Die Sorte Mohican sowie einige Göttinger und NPZ Linien wiesen geringe Gehalte an Sinapin, bzw. Sinapoylglucose und an den anderen SE auf. Auffallend war, daß die geprüften Resynthesen nicht durch extreme Gehalte an Sinapinsäureestern auffielen.

Legende zur nachfolgenden Tabelle 4

${ }^{1}$ berechnet als Sinapinsäure,

2 HPLC-Daten aus 2001/2002, vergl. Manuskript I

A DH Linie aus der Kreuzung DH Mansholts' x Express

${ }^{B}$ Göttinger Material; Feldnummer Ernte 2002

${ }^{C}$ DH Linie aus der Kreuzung DH Mansholts' x DH Samourai

${ }^{D}$ Polnische Sorte bzw. DH-Linie, von Prof. Jan Olejniczak, Posen, Polen, zur Verfügung gestellt

Die HPLC-Werte stellen Ergebnisse von Analysen einzelner Samenproben dar, sofern nicht anders erläutert. Die NIRS-Ergebnisse der Erntejahre 2002 und 2003 stellen Mittelwerte von drei gemessenen Selbstungen dar. 
Tab. 4: Gehalte an Sinapinsäureestern (SE) ausgewählte Genotypen mit besonders niedrigen und besonders hohen Gehalten (Angaben in mg g $^{-1}$ Samen)

\begin{tabular}{|c|c|c|c|c|c|}
\hline Genotyp & Herkunft & HPLC & $\begin{array}{c}\text { NIRS } \\
\text { Ernte 2002,Gö }\end{array}$ & $\begin{array}{c}\text { NIRS } \\
\text { Ernte2003,Gö }\end{array}$ & $\begin{array}{c}\text { NIRS } \\
\text { (gemittelt) }\end{array}$ \\
\hline \multicolumn{6}{|c|}{ Gesamt $S E^{1}$} \\
\hline $\mathrm{DH} 68$ & $M \times E^{A}$ & 5,9 & 3,4 & 3,1 & 3,3 \\
\hline 2175 & $W(3278-3)^{B}$ & $*$ & 3,6 & 3,1 & 3,4 \\
\hline $\mathrm{DH} 19$ & $M \times E^{A}$ & * & 3,7 & 4,2 & 4,0 \\
\hline $\mathrm{DH} 41$ & $M \times E^{A}$ & $4,9^{2}$ & 4,4 & 4,3 & 4,4 \\
\hline 1982 & $M \times S(3451-3)^{C}$ & * & 4,4 & 4,4 & 4,4 \\
\hline Skz. 33-4 & Skrzeszowicki ${ }^{\mathrm{D}}$ & 3,2 & 5,1 & 5,9 & 5,5 \\
\hline DH-Mansh & & 4,9 & 4,0 & 4,7 & 4,4 \\
\hline Skrzeszon & & 6,7 & 7,0 & 7,2 & 7,1 \\
\hline Mohican & & $8,1^{2}$ & 7,3 & 7,5 & 7,4 \\
\hline \multicolumn{2}{|c|}{ Express (NAP 0001) } & $7.5^{2}$ & 8,2 & 7,8 & 8,0 \\
\hline 2051 & NPZ (3596-2) & 9,9 & 9,7 & 9,6 & 9,7 \\
\hline 2276 & $\mathrm{DH} 0120^{\mathrm{D}}$ & 9,7 & 9,4 & 10,0 & 9,7 \\
\hline \multicolumn{6}{|l|}{ Sinapin } \\
\hline 2175 & W (3278-3) & * & 2,5 & 3,0 & 2,8 \\
\hline Mohican & & $4,9^{2}$ & 2,6 & 3,5 & 3,1 \\
\hline 2082 & NPZ (3492-4) & * & 3,7 & 3,9 & 3,8 \\
\hline 2018 & NPZ (3491-2) & * & 3,5 & 4,2 & 3,9 \\
\hline DH 149 & $M \times E^{A}$ & * & 3,8 & 4,2 & 4,0 \\
\hline \multirow{2}{*}{\multicolumn{2}{|c|}{$\begin{array}{l}\text { DH-Mansholts } \\
\text { Express (NAP 0001) }\end{array}$}} & 6,4 & 5,1 & 5,4 & 5,3 \\
\hline & & $6,9^{2}$ & 6,5 & 6,5 & 6,5 \\
\hline 2230 & $W(3098-3)^{B}$ & $*$ & 9,5 & 8,1 & 8,8 \\
\hline 2051 & NPZ (3596-2) & 8,8 & 9,7 & 8,5 & 9,1 \\
\hline \multicolumn{6}{|c|}{ Sinapoylglucose } \\
\hline $\mathrm{DH} 68$ & $M \times E^{A}$ & 0,8 & 0,4 & 0,2 & 0,3 \\
\hline $\mathrm{DH} 45$ & $M \times E^{A}$ & * & 1,1 & 0,5 & 0,8 \\
\hline $\mathrm{DH} 6$ & $M \times E^{A}$ & * & 0,4 & 0,5 & 0,5 \\
\hline 1982 & $M \times S(3451-3)^{B}$ & $*$ & 0,3 & 0,6 & 0,5 \\
\hline DH-Mansh & & 0,5 & 0,3 & 0,7 & 0,5 \\
\hline & $2.2^{2}$ & 2,6 & 1,8 & 2,2 \\
\hline \multicolumn{2}{|c|}{$\begin{array}{l}\text { Express (NAP 0001) } \\
\text { Mohican }\end{array}$} & $3,9^{2}$ & 5,3 & 3,9 & 4,6 \\
\hline 2018 & NPZ (3491-2) & * & 5,1 & 4,4 & 4,8 \\
\hline 2084 & NPZ (3492-1) & * & 4,6 & 4,6 & 4,6 \\
\hline \multicolumn{6}{|c|}{ andere $S E^{1}$} \\
\hline $\mathrm{DH} 68$ & $M \times E^{A}$ & 0,3 & 0,0 & 0,0 & 0,0 \\
\hline DH 128 & $M \times E^{A}$ & * & 0.0 & 0,0 & 0.0 \\
\hline $\mathrm{DH} 19$ & $M \times E^{A}$ & * & 0,3 & 0,0 & 0,2 \\
\hline 2101 & $W(3138-3)^{B}$ & * & 0,0 & 0.0 & 0,0 \\
\hline \multicolumn{2}{|c|}{ DH-Mansholts } & 0,2 & 0,1 & 0,0 & 0,1 \\
\hline \multicolumn{2}{|c|}{ Express (NAP 0001) } & $1.5^{2}$ & 0,7 & 0,8 & 0,8 \\
\hline \multicolumn{2}{|c|}{$\begin{array}{l}\text { Express (NAP 0001) } \\
\text { Mohican }\end{array}$} & $2,5^{2}$ & 1,2 & 1,6 & 1,4 \\
\hline 2084 & NPZ (3492-1) & * & 1,8 & 2,2 & 2,0 \\
\hline 2018 & NPZ (3491-2) & * & 1,7 & 2,3 & 2,0 \\
\hline
\end{tabular}




\section{Genetische Variation für den Gehalt an Sinapinsäurestern im Raps und Entwicklung von NIRS Kalibrierungen}

\subsection{Zusammenfassung (ausführliche Darstellung siehe Manuskript I)}

Die Verbesserung der Schrot- und Proteinqualität von Raps zur höherwertigen Nutzung nicht nur als Futtermittel, sondern auch als Lebensmittel ist ein zunehmend wichtiger werdendes Ziel in der Züchtung von '00'-Qualitätsraps (Brassica napus L.). Die Rapssaat zeichnet sich im Unterschied zu anderen Ölsaaten durch einen hohen Gehalt an Phenolsäureestern aus. Nach der Ölextraktion verbleiben diese im Schrot und führen zu einer dunklen Verfärbung und zu einem bitteren, adstringierenden Geschmack des Schrots und daraus hergestellter Proteinprodukte. Unter den im Raps vorkommenden Phenolsäureestern dominieren mit etwa 80\% die sinapinsäurehaltigen Ester (SE).

Das Ziel der vorliegenden Arbeit war die Untersuchung der genetischen Variation in einem großen Rapssortiment für Sinapoylcholin (Sinapin), Sinapoylglucose und Sinapinsäure sowie für einige andere, in geringerer Konzentration vorkommender sinapinsäurehaltiger Ester. Da die freie Sinapinsäure und die anderen Sinapinsäureester nur in geringer Konzentration nachgewiesen werden konnten, wurden sie in der Gruppe 'andere SE' zusammengefasst. Weiteres Ziel der Arbeit war es, Nah-Infrarot ReflektionsSpektroskopische (NIRS) Kalibrierungen für diese Verbindungen zu entwickeln, um damit Genotypen mit einem geringen Gesamtgehalt an SE identifizieren zu können. Eine genotypisch diverse Samenkollektion an Winterrapsen (Sorten, Zuchtlinien, GenbankMaterial, resynthetisierter Raps) aus verschiedenen Erntejahren und Umwelten wurde mit Hilfe der HPLC auf ihren Gehalt und ihre Zusammensetzung an SE untersucht. Die NIRS-Spektren dieser Proben wurden aufgezeichnet und mit Hilfe der HPLCReferenzwerte wurden zunächst vorläufige NIRS-Kalibrierungen entwickelt. Diese wurden dann verwendet, um zusätzliche im Hinblick auf ihren SE-Gehalt interessante Proben zu identifizieren und in die Kalibrierung zu integrieren. Die abschließend erstellte NIRS Kalibrierung enthielt 549 Spektren unterschiedlichster Samenproben mit einer Variation im Gesamtgehalt an SE-Verbindungen von 2,7 bis $13,1 \mathrm{mg}$ Sinapinsäure $\mathrm{g}^{-1}$ Samen. Eine erhebliche Variation wurde auch für die einzelnen Komponenten Sinapin $\left(3,2-11,7 \mathrm{mg} \mathrm{g}^{-1}\right)$, Sinapoylglucose $\left(0,0-6,5 \mathrm{mg} \mathrm{g}^{-1}\right)$ und für die 'andere SE' (0,0 - 3.9 mg Sinapinsäure $\mathrm{g}^{-1}$ ) gefunden. Sinapin war mit einem Mittel von 65\% der Gesamt-SE die vorherrschende Komponente, mit einer Variation von $25 \%$ bis über $95 \%$. Eine erhebliche Variation für den relativen Gehalt an Sinapoylglucose $(0-50 \%)$ und an den anderen SE $(0-45 \%)$ konnte ebenfalls nachgewiesen werden. Die Kalibrations- 
gleichungen erklärten nach Kreuzvalidierung $\left(R^{2}{ }_{c v}\right)$ von $69 \%$ (andere SE) über $79 \%$ (Sinapoylglucose) und 80\% (Gesamt-SE) bis zu 81\% (Sinapin) der Varianz der HPLCReferenzwerte. Die Standardfehler nach Kreuzvalidierung (SECV) variierten zwischen 0,45 (andere SE) und 0,77 mg Sinapinsäure $\mathrm{g}^{-1}$ Samen (Gesamt-SE). Das Verhältnis SD/SECV für Gesamt-SE und Sinapin betrug 2,3 und zeigt damit an, dass diese Kalibrationsgleichungen für die Identifizierung von Genotypen mit einem niedrigen Gehalt an SE in entsprechenden Züchtungsprogrammen verwendet werden können. Für Sinapoylglucose lag das SD/SECV-Verhältnis bei 2,2 und für 'andere SE' bei 1,8. Genotypen mit einem im Vergleich zu Standardsorten um 30-40\% verringerten Gesamtgehalt an SE konnten identifiziert und nach Überprüfung in einem Feldversuch bestätigt werden. Die NIRS Kalibrationsgleichungen und die identifizierten Genotypen mit einem niedrigen Gesamtgehalt an SE könnten für die Züchtung auf einen niedrigen SE Gehalt im Rahmen entsprechender Züchtungsprogramme nützlich sein. 


\section{Genotyp x Umwelt Interaktionen, Heritabilitäten und Merkmalskorrela- tionen für den Gehalt an Sinapinsäureestern im Winterraps}

\subsection{Zusammenfassung (ausführliche Darstellung siehe Manuskript II)}

Die Verbesserung der Schrot- und Proteinqualität von Raps zur höherwertigen Nutzung nicht nur als Futtermittel, sondern auch als Lebensmittel ist ein zunehmend wichtiger werdendes Ziel in der Züchtung von '00'-Qualitätsraps (Brassica napus L.). Der Gehalt an Phenolsäureestern im Samen des Raps ist etwa 30 mal höher im Vergleich zur Sojabohne. Zu einem großen Teil bestehen sie aus Estern der Sinapinsäure (SE) und machen etwa 1-2 \% der Samentrockenmasse aus. Die SE tragen zu dem bitteren, adstringierenden Geschmack und der dunklen Farbe von Produkten bei, die unter Verwendung von Rapsprotein hergestellt werden. Für die Züchtung auf einen reduzierten Gehalt an SE-Verbindungen ist die Kenntnis der Genotyp x Umwelt (GxU)-Interaktionen für dieses Merkmal sowie von möglicherweise vorhandenen Korrelationen zu anderen wertbestimmenden Sameninhaltstoffen von Bedeutung.

Das Ziel der vorliegenden Arbeit war es, die Genotyp-Umwelt-Interaktionen für den SEGehalt und die -Zusammensetzung in drei doppelthaploiden Rapspopulationen zu untersuchen und Merkmalskorrelationen zu agronomisch relevanten Qualitätsmerkmalen festzustellen. Mittels HPLC-Analyse konnten folgende Sinapinsäureverbindungen nachgewiesen werden: Sinapoylcholin (Sinapin), Sinapoylglucose und nur in geringerer Konzentration vorkommende Sinapinsäure und andere Sinapinsäureester. Die Sinapinsäure und die anderen Sinapinsäureester wurden sie in der Gruppe 'andere SE' zusammengefasst.

Der mittlere Sinapinanteil an den Gesamt-SE Verbindungen variierte bei den drei Populationen zwischen 58\% und 72\%. Der relative mittlere Anteil an Sinapoylglucose variierte zwischen $17 \%$ und $20 \%$ und für die Gruppe der anderen SE konnte eine Variation zwischen 10\% und 22\% festgestellt werden. Die Varianzanalyse zeigte in allen drei Populationen hoch signifikante Effekte für den Genotyp, die Umwelt und die GxUInteraktionen sowohl für den Gesamtgehalt an SE-Verbindungen als auch für die einzelnen Sinapinsäureverbindungen. Einzig in einer Population erwiesen sich die Umwelteffekte für die Gruppe der anderen SE als nicht signifikant. In Population I und III waren die genotypischen Varianzkomponenten erheblich größer als die GxUVarianzkomponenten. Die sich ergebenden Heritabilitäten für die einzelnen SE und für den Gesamtgehalt waren im allgemeinen hoch und variierten zwischen 0,78 und 0,93. In 
Population II waren Varianzkomponenten für die GxE-Interaktionen größer als die für den Genotyp. Die Heritabilitäten variierten hier zwischen 0,57 und 0,70.

Der Gesamtgehalt an SE-Verbindungen war hoch signifikant positiv korreliert mit dem Gehalt an den einzelnen SE-Verbindungen. Dies zeigt, dass eine Reduzierung im Gesamtgehalt durch Selektion auf niedrige Gehalte an jeder einzelnen SE-Verbindung erreicht werden kann. Es konnte kein signifikanter Zusammenhang zwischen dem Gesamtgehalt an SE-Verbindungen und dem Öl-, Protein- und Glucosinolatgehalt in den Samen festgestellt werden. Die Ergebnisse zeigen, daß eine effektive Selektion auf einen niedrigen SE-Gehalt mit einem vergleichsweise geringen Prüfaufwand möglich sein sollte, vorausgesetzt, das Zuchtmaterial zeigt eine ausreichend hohe genotypische Variation. Es ist nicht zu erwarten, dass eine Verringerung des SE-Gehaltes im Samen zu einer Veränderung in anderen relevanten Qualitätsmerkmalen führt. 


\section{Zusammenfassende Diskussion der züchterischen Möglichkeiten für die weitere Reduktion des Gehaltes an Phenolsäuren im Raps}

Im Rahmen der vorliegenden Arbeit konnten Genotypen mit einem im Vergleich zu Standardsorten um 30 bis $40 \%$ reduzierten Gehalt an Sinapinsäureestern nachgewiesen werden. Die Identifizierung zusätzlicher Genotypen mit geringen Gehalten könnte durch die Untersuchung bisher nicht berücksichtigten Materials (Sommerraps, ausländisches Material) erreicht werden. Für eine schnelle, zerstörungsfreie und simultan zur Analyse anderer Inhaltsstoffe durchzuführende Vorselektion von interessanten Genotypen bietet sich die NIRS an. Unter dem geprüften Material konnten die Linie DH Mansholts' und verwandte DH-Linien und die aus der polnischen Winterrapssorte Skrzeszowicki erhaltene Linie Skrzeszowicki 33-4 (Prof. Jan Olejniczak, Posen, Polen) mit besonders geringen Gehalten an Sinapinsäureestern identifiziert werden. Die Kreuzung der polnischen Linie mit DH Mansholts' und verwandten Linien erscheint viel versprechend, um in den Nachkommenschaften Linien mit weiter reduzierten Gehalten identifizieren zu können. Abgesehen von diesem Material wiesen alle anderen Genotypen deutlich höhere Gehalte auf. Allerdings wiesen zusätzliche andere Genotypen für bestimmte einzelne Sinapinsäureester relativ geringe Gehalte auf (Tab. 4). Dieses Material könnte ebenfalls gezielt mit in die Kreuzungen einbezogen werden. Die nachgewiesenen mittleren bis hohen Heritabilitäten für die einzelnen Sinapinsäureester und den Gesamtgehalt (siehe Manuskript II) sowie die Verfügbarkeit der NIRS-Kalibrierungen erleichtern dabei die Identifizierung interessanter Genotypen in den Nachkommenschaften.

Eine weitere naheliegende Möglichkeit die Gehalte an Sinapinsäureestern im Raps erheblich zu reduzieren, bietet die Kreuzung mit transgenen Linien, die einen drastisch reduzierten Gehalt aufweisen (Nair et al. 2000, Hüsken et al. 2005a,b). In einem Gewächshausversuch wurden transgene T3-Linien zusammen mit dem untransformierten Ausgangsgenotyp 'Drakkar' (Hüsken et al. 2005a,b) und DH Mansholts sowie Skz. 33-4 geprüft (Möllers und Becker 2005). Die Ergebnisse zeigten für die untransformierte Sorte mit $8,7 \mathrm{mg}$ Sinapinsäure $\mathrm{g}^{-1}$ Samen normal hohe Werte (Tab. 5). Im Vergleich dazu zeigten die im Rahmen dieser Arbeit identifizierten konventionellen Linien DH Mansholts und Skz. 33-4 um bis zu etwa 50\% niedrigere Werte. Die transgenen Linien wiesen dagegen eine ca. 70-80\% Reduktion auf. 
Tab. 5: Vergleich der Gesamtgehalte an Sinapinsäureestern (mg/g Samen) in transgenen und konventionellen Rapslinien (Prüfung im Gewächshaus Frühjahr 2004; verändert nach Möllers und Becker 2005)

\begin{tabular}{llcccc}
\hline Genotyp & Typ & $\mathrm{n}$ & Mittelwert & SD & \% (vom MW) \\
\hline cv. Drakkar, & konventionell & 13 & 8,7 & 0,60 & $=100$ \\
Kontrolle & & 20 & 2,7 & 0,37 & 31 \\
1501.24 .18 & transgen & 20 & 3,0 & 0,38 & 35 \\
1501.24 .1 & transgen & 20 & 2,5 & 0,61 & 29 \\
1502.15 .7 & transgen & 20 & 2,0 & 0,47 & 23 \\
1502.15 .16 & transgen & & & & \\
& & 20 & 4,7 & 0,51 & 54 \\
Skz. 33-4 & konventionell & 20 & 4,2 & 0,23 & 49 \\
DH Mansholts & konventionell & 20 & & & \\
\hline
\end{tabular}

Nair et al. (2000) berichten von einer um etwa 40\%igen Reduktion von Sinapinsäureestern in transgenen Rapspflanzen. Da Nair et al. (2000) einen von Hüsken et al. $(2005 a, b)$ verschiedenen transgenen Ansatz verfolgt haben, könnte auch eine Kombination der relevanten Transgene aus diesen Arbeiten durch Kreuzung der entsprechenden Genotypen in weiter reduzierten Gehalten resultieren. Hüsken et al. (2005b) diskutieren, dass die Verwendung des starken konstitutiven 35S-Promotors in Ergänzung zu dem in ihren Versuchen verwendeten samenspezifischen NapinPromotors auch zu einer zusätzlichen Reduzierung der Sinapinsäureester führen könnte. So wird Sinapin spezifisch in den Samen synthetisiert (Milkowski et al. 2004), und die mit Hilfe des Napin-Promotors erzielte erhebliche Reduktion der Sinapinsäureester spricht ebenfalls für eine überwiegend in den Samen stattfindende und durch den Genotyp des Embryos bestimmte Synthese. Diese Hypothese wird auch durch Ergebnisse von Untersuchungen zum Einfluss des Pollengenotyps auf die Gehalte an Sinapinsäureestern im Samen unterstützt (Hom 2004, und eigene nicht dargestellte Ergebnisse). Dennoch kann nicht ausgeschlossen werden, dass Sinapoylglucose und möglicherweise andere Ester aus dem maternalen Gewebe in die Samen transportiert werden.

Sinapoylglucose und Sinapoylcholine (Sinapin) machen zusammen den Hauptanteil der Sinapinsäureverbindungen im Samen aus. Sinapoylglucose stellt dabei die unmittelbare Vorstufe in der Synthese des Sinapins dar (Abb. 1) Das für die Synthese von Sinapoylglucose relevante Gen, die Sinapinsäure-Glucosyltransferase (SGT), wurde von Milkowski et al. (2000) kloniert. Weiterführende Studien haben gezeigt, dass es im Raps 
nur 2 Kopien des SGT-Gens gibt, die dem Kohl und dem Rübsengenom zugeordnet werden können (Milkowski et al. 2004). Das SGT-Gen wurde in den AntisenseVersuchen von Hüsken et al. (2005a,b) verwendet. Ihre Ergebnisse zeigen, dass es nach Hemmung der Expression des SGT-Gens nicht zu einer Anreicherung von freier Sinapinsäure und anderen Sinapinsäureestern kommt. Für die Sinapinsäure könnte dies durch eine 'Feedback'-Hemmung auf vorgelagerte Enzyme erklärt werden. Die Synthese der anderen Sinapinsäureester wird möglicherweise unterbunden, weil Sinapoylglucose wahrscheinlich die Vorstufe auch in ihrem Biosyntheseweg ist (Milkowski et al. 2004). Unklar ist, ob es zu einem Anstieg anderer Phenolsäurester im Raps kommt. Bereits bei Thies (1982) gibt es allerdings Hinweise, daß Genotypen mit einem geringen Gehalt an Sinapinsäureestern auch einen verringerten Gehalt an anderen Phenolsäuren aufweisen.

Die offensichtlich geringe Kopienzahl des SGT-Gens in dem normalerweise durch Duplikationen gekennzeichneten amphidiploiden Raps läßt es aussichtsreich erscheinen, durch Mutationsauslösung nicht transgene Genotypen mit einem möglicherweise noch geringeren Gehalt an Sinapinsäureestern zu erzeugen. Noch aussichtsreicher im Hinblick auf die Identifizierung von SGT-Mutanten ist die Durchführung der Mutationsversuche in einer der beiden Ausgangsarten des Raps. Die vorhandenen NIRS-Kalibrierungen können dabei sehr von Nutzen für die Analyse einer großen Anzahl an Samenproben sein.

Bis zum Abschluß der vorliegenden Arbeit war es nicht klar, ob die erreichte Reduzierung im Gehalt an Sinapinsäureestern möglicherweise bereits ausreicht, um eine signifikante Verbesserung in der Qualität des Rapsschrots und daraus hergestellter Proteinprodukte zu erreichen, oder ob die oben genannten Ansätze zur weiteren Reduzierung verfolgt werden müssen. Interessant in diesem Zusammenhang ist, daß es bereits seit geraumer Zeit erfolgreiche technologische Ansätze zur Reduktion des Gehalts an Sinapinsäureestern im Rapsschrot gibt (Tayaranian 1991). 


\section{$8 \quad$ Zusammenfassung}

Die Verbesserung der Schrot- und Proteinqualität des Rapskorns zur hochwertigen Nutzung nicht nur als Futtermittel, sondern auch als Lebensmittel ist ein zunehmend wichtiger werdendes Ziel in der Züchtung von '00'-Qualitätsraps (Brassica napus L.). Die Rapssaat zeichnet sich im Unterschied zu anderen Ölsaaten durch einen hohen Gehalt an Phenolsäureestern aus. Nach der Ölextraktion verbleiben diese im Schrot und führen zu einer dunklen Verfärbung und zu einem bitteren, adstringierenden Geschmack des Schrots und daraus hergestellter Proteinprodukte. Unter den im Raps vorkommenden Phenolsäureestern dominieren mit etwa 80\% die sinapinsäurehaltigen Ester (SE).

Das Ziel der vorliegenden Arbeit war die Untersuchung der genetischen Variation in einem großen Rapssortiment für Sinapoylcholin (Sinapin), Sinapoylglucose und Sinapinsäure sowie für einige andere sinapinsäurehaltiger Ester. Da die freie Sinapinsäure und die anderen Sinapinsäureester nur in geringer Konzentration nachgewiesen werden konnten, wurden sie in der Gruppe 'andere SE' zusammengefasst. Weiteres Ziel der Arbeit war es, Nah-Infrarot ReflektionsSpektroskopische (NIRS) Kalibrierungen für diese Verbindungen zu entwickeln, um damit Genotypen mit einem geringen Gesamtgehalt an SE identifizieren zu können. Eine genotypisch diverse Samenkollektion an Winterrapsen (Sorten, Zuchtlinien, GenbankMaterial, resynthetisierter Raps) aus verschiedenen Erntejahren und Umwelten wurde mit Hilfe der HPLC auf ihren Gehalt und ihre Zusammensetzung an SE untersucht. Die NIRS-Spektren dieser Proben wurden aufgezeichnet und mit Hilfe der HPLCReferenzwerte wurden zunächst vorläufige NIRS-Kalibrierungen entwickelt. Diese wurden dann verwendet, um zusätzliche im Hinblick auf ihren SE-Gehalt interessante Proben zu identifizieren und in die Kalibrierung zu integrieren. Die abschließend erstellte NIRS Kalibrierung enthielt 549 Spektren unterschiedlichster Samenproben mit einer Variation im Gesamtgehalt an SE-Verbindungen von 2,7 bis $13,1 \mathrm{mg}$ Sinapinsäure $\mathrm{g}^{-1}$ Samen. Eine erhebliche Variation wurde auch für die einzelnen Komponenten Sinapin $\left(3,2-11,7 \mathrm{mg} \mathrm{g}^{-1}\right)$, Sinapoylglucose $\left(0,0-6,5 \mathrm{mg} \mathrm{g}^{-1}\right)$ und für die Gruppe der anderen SE $\left(0,0-3.9 \mathrm{mg}\right.$ Sinapinsäure $\left.\mathrm{g}^{-1}\right)$ gefunden. Sinapin war mit einem Mittel von $65 \%$ der Gesamt-SE die vorherrschende Komponente, mit einer Variation von 25\% bis über 95\%. Eine erhebliche Variation für den relativen Gehalt an Sinapoylglucose $(0-50 \%)$ und an den anderen SE $(0-45 \%)$ konnte ebenfalls nachgewiesen werden. Die Kalibrationsgleichungen erklärten nach Kreuzvalidierung $\left(\mathrm{R}_{\mathrm{cv}}^{2}\right)$ von 69\% (andere SE) über 79\% (Sinapoylglucose) und 80\% (Gesamt-SE) bis zu 81\% (Sinapin) der Varianz der HPLC-Referenzwerte. Die Standardfehler nach Kreuzvalidierung (SECV) variierten 
zwischen 0,45 (andere SE) und 0,77 $\mathrm{mg}$ Sinapinsäure $\mathrm{g}^{-1}$ Samen (Gesamt-SE). Das Verhältnis SD/SECV für Gesamt-SE und Sinapin betrug 2,3 und zeigt damit an, dass diese Kalibrationsgleichungen für die Identifizierung von Genotypen mit einem niedrigen Gehalt an SE in entsprechenden Züchtungsprogrammen verwendet werden können. Für Sinapoylglucose lag das SD/SECV-Verhältnis bei 2,2 und für Gruppe der anderen SE bei 1,8. Genotypen mit einem im Vergleich zu Standardsorten um 30-40\% verringerten Gesamtgehalt an SE konnten identifiziert und nach Überprüfung in einem Feldversuch bestätigt werden. Die NIRS Kalibrationsgleichungen und die identifizierten Genotypen mit einem niedrigen Gesamtgehalt an SE könnten für die Züchtung auf einen niedrigen SE Gehalt im Rahmen entsprechender Züchtungsprogramme nützlich sein.

Ziel der vorliegenden Arbeit war es weiterhin, ein möglichst großes, genetisch divergentes Winterraps-Sortiment bestehend aus Sorten, Zuchtlinien, Genbank-Material und resynthetisiertem Raps auf seine phänotypische Variation im Gesamtgehalt und in der Zusammensetzung an sinapinsäurehaltigen Verbindungen zu untersuchen. Genotypen mit vergleichsweise niedrigen und hohen Gehalten sollten dann im Rahmen von mehrortigen Feldversuchen geprüft werden, um genotypische Unterschiede festzustellen.

Für die Untersuchung der genotypischen Variation wurden Ernteproben aus Göttingen der Jahre 1997 bis 2002 verwendet. Insgesamt wurden 2549 Spektren von DHPopulationen (DH Mansholts $x$ DH Samourai, DH Mansholts' $x$ Express, Apex $x$ Mohican, Hoch-Ölsäure-Material, DH-Linien der Firma Semundo), von WinterrapsMaterial der Genbank IPK Gatersleben, Aussenstelle Malchow, nach Anbau in Göttingen, und von resynthetisierten Rapsen ausgewertet. Darüber hinaus wurden von der Norddeutschen Pflanzenzucht Hans-Georg Lembke KG (NPZ), Hohenlieth, und der Deutschen Saatveredlung (DSV), Lippstadt, NIRS-Spektren von ihrem Zuchtmaterial der Ernte 2001 zur Verfügung gestellt. Nach Auswertung der Spektren mit Hilfe der NIRSKalibrierungen wurde Saatgut von den Genotypen mit geringen Gehalten angefordert. Diese wurden während der Jahre 2001 bis 2002 im Zuchtgarten des Versuchsguts Reinshof, Universität Göttingen, geprüft.

Vergleichsweise sehr geringe SE-Gehalte um die $5 \mathrm{mg}$ Sinapinsäure $\mathrm{g}^{-1}$ Samen wurden bei der Linie DH Mansholts' und weiteren mit diesem Genotyp verwandten Linien sowie in der nach Mutagenese aus der polnischen Sorte Skrzeszowicki erhaltenen Linie Skz. 33-4 nachgewiesen. Linien mit den höchsten SE-Gehalten enthielten bis zu $10 \mathrm{mg}$ Sinapinsäure $\mathrm{g}^{-1}$ Samen. Die Sorten Express, Mohican und Skrzeszowicki wiesen SE- 
Gehalte um die $8 \mathrm{mg}$ Sinapinsäure $\mathrm{g}^{-1}$ Samen auf. Die Sorte Mohican sowie einige Göttinger und NPZ Linien wiesen geringe Gehalte an Sinapin, bzw. Sinapoylglucose und an den anderen SE auf.

Für die Züchtung auf einen reduzierten Gehalt an SE-Verbindungen ist die Kenntnis der Genotyp x Umwelt (GxU)-Interaktionen für dieses Merkmal sowie von möglicherweise vorhandenen Korrelationen $\mathrm{zu}$ anderen wertbestimmenden Sameninhaltstoffen von Bedeutung. Ein weiteres Ziel der vorliegenden Arbeit war es daher, die Genotyp-UmweltInteraktionen für den SE-Gehalt und die -Zusammensetzung in drei doppelthaploiden Rapspopulationen zu untersuchen und Merkmalskorrelationen zu agronomisch relevanten Qualitätsmerkmalen festzustellen.

Der mittlere Sinapinanteil an den SE-Verbindungen variierte bei den drei Populationen zwischen 58\% und 72\%. Der relative mittlere Anteil an Sinapoylglucose variierte zwischen $17 \%$ und $20 \%$ und für die Gruppe der anderen SE konnte eine Variation zwischen $10 \%$ und 22\% festgestellt werden. Die Varianzanalyse zeigte in allen drei Populationen hoch signifikante Effekte für den Genotyp, die Umwelt und die GxUInteraktionen sowohl für den Gesamtgehalt an SE-Verbindungen als auch für die einzelnen Sinapinsäureverbindungen. Einzig in einer Population erwiesen sich die Umwelteffekte für die Gruppe der anderen SE als nicht signifikant. In Population I und III waren die genotypischen Varianzkomponenten erheblich größer als die GxUVarianzkomponenten. Die sich ergebenden Heritabilitäten für die einzelnen SE und für den Gesamtgehalt waren hoch und variierten zwischen 0,78 und 0,93. In Population II waren Varianzkomponenten für die GxE-Interaktionen größer als die für den Genotyp. Die Heritabilitäten variierten hier zwischen 0,57 und 0,70.

Der Gesamtgehalt an SE-Verbindungen war hoch signifikant positiv korreliert mit dem Gehalt an den einzelnen SE-Verbindungen. Dies zeigt, dass eine Reduzierung im Gesamtgehalt durch Selektion auf niedrige Gehalte an jeder einzelnen SE-Verbindung erreicht werden kann. Es konnte kein signifikanter Zusammenhang zwischen dem Gesamtgehalt an SE-Verbindungen und dem Öl-, Protein- und Glucosinolatgehalt in den Samen festgestellt werden. Die Ergebnisse zeigen, dass eine effektive Selektion auf einen niedrigen SE-Gehalt mit einem vergleichsweise geringen Prüfaufwand möglich sein sollte, vorausgesetzt, das Zuchtmaterial zeigt eine ausreichend hohe genotypische Variation. Es ist nicht zu erwarten, dass eine Verringerung des SE-Gehaltes im Samen zu einer Veränderung in anderen relevanten Qualitätsmerkmalen führt. 


\section{$9 \quad$ Literaturverzeichnis}

Bell, J.M., 1984: Nutrients and Toxicants in Rapeseed Meal. A review. J. Anim. Sci. 58: 996-1010.

Bell, J.M., 1993: Factors affecting the nutritional value of canola meal. A review. Can. J. Anim. Sci. 73: 679-697.

Bouchereau, A., J. Hamelin, M. Renard and F. Larher 1992: Structural changes in sinapic acid conjugates during seedling development of rape. Plant Physiol. Biochem. 30: 467-475.

Bouchereau, A., J. Hamelin, I. Lamour, M. Renard and F. Larher 1991: Distribution of sinapine and related compounds in seeds of Brassica and allied Genera. Phytochemistry 30: 1873-1881.

Chapple, C., T. Vogt, B.E. Ellis and C.S. Somerville1992: An Arabidopsis mutant defective in the general phenylproanoid pathway. The Plant Cell 4: 1413-1424.

Dabrowski, K.J. and F.W. Sosulski 1984: Composition of free and hydrolyzable phenolic acids in defatted flours of ten oilseeds. J. Agric. Food Chem. 32: 128-130.

FAO, 2004: http: www.fao.org

Griffith, D.W., 1989: Polyphenolics and their possible effects on nutritive value. Aspects of Applied Biology 19: 93-103.

Hom, N.H., 2004: Pollen genotype effects on seed quality and selection of single seeds by Near-Infrared Reflectance Spectroscopy (NIRS) in winter oilseed rape. Klartext Verlag Göttingen. ISBN: 3-9808714-4-4. http://webdoc.sub.gwdg.de/diss/2004/hom/hom.pdf

Hüsken, A. 2001: Untersuchungen zum Nachweis und zur Vererbung von Sinapoyl im Rapssamen. Masterarbeit, Institut für Pflanzenbau und Pflanzenzüchtung, Universität Göttingen.

Hüsken, A., A. Baumert, C. Milkowski, H.C. Becker, D. Strack and C. Möllers 2005a: Resveratrol glucoside (Piceid) synthesis in seeds of transgenic oilseed rape (Brassica napus L.). Theor. Appl. Genet.: DOI 10.1007/s00122-005-0085-1

Hüsken, A., A. Baumert, D. Strack, H.C. Becker, C. Möllers and C. Milkowski 2005b: Reduction of sinapate ester content in transgenic oilseed rape (Brassica napus) by dsRNAi-based suppression of BnSGT1 gene expression. Mol. Breed, in press.

Kolodziejczyk, P., W. Xiaoyan, M. Marianchuk, L. Wanli and R. Amarowicz 1999: Phenolics In Rapeseed: Capillary Electrophoresis as a novel analytical method for 
detection of sinapine, sinapic acid esters and ferulates. $10^{\text {th }}$ International Rapeseed Congress, Canberra

Kozlowska, H., M. Naczk, F. Shahidi and R. Zadernowski 1990: Phenolic acids and tannins in rapeseed and canola, pp. 193-210. In: F. Shahidi (Ed.), Canola and Rapeseed. Production, Chemistry, Nutrition and Processing Technology. Van Nostrand Reinhold, New York.

Kräling, K., G. Röbbelen and W. Thies 1991: Genetic variation of the content of sinapoyl esters in seeds of rape, B. napus. Plant Breeding 106: 254-257.

Leckband, G., 2002: NAPUS 2000 - Gesunde Lebensmittel aus transgener Rapssaat. In: Vom Genom zur Sorte, Vorträge für Pflanzenzüchtung 54: 167-172.

Lorenzen, M., V. Racicot, D. Strack and C. Chapple 1996: Sinapic acid ester metabolism in wild type and a sinapoylglucose-accumulating mutant of Arabidopsis. Plant Physiol. 112: 1625-1630.

Lühs, W., R. Baetzel and W. Friedt 2000: Zur Kombinierbarkeit von hoher Saatgutqualität und wertvollen Korninhaltsstoffen bei Raps (Brassica napus L.): Möglichkeiten und Grenzen. Bericht über die 51. Arbeitstagung der Vereinigung österreichischer Pflanzenzüchter: 1-11.

Milkowski, C., A. Baumert and D. Strack 2000: Cloning and heterologous expression of a rape cDNA encoding UDP-glucose:sinapate glucosyltransferase. Planta 211: 883886.

Milkowski, C., A. Baumert, D. Schmidt, L. Nehlin and D. Strack 2004: Molecular regulation of sinapate ester metabolism in Brassica napus: expression of genes, properties of the encoded proteins and correlation of enzyme activities with metabolite accumulation. Plant J. 38: 80-92.

Möller, P., O. Olsen, A. Plöger, K.W. Rasmussen and H. Sörensen 1985: Quantitative analysis of individual glucosinolates in double low oilseed rape by HPLC of intact glucosinolates. In: Advances in the production and utilization of cruciferous crops. $\mathrm{H}$. Sörensen (Ed.). Nijhoff/Junk Dordrecht, NL.

Möllers, C. 2004: Potential and future prospects for rapeseed oil. In: F.D. Gunstone (ed.): Rapeseed and Canola Oil - Production, Processing, Properties and Uses. Blackwell Publishing, Oxford, UK. Pp. 186-217.

Möllers, C. and H.C. Becker 2005: Genetische Variation und Vererbung von Sinapin- und Tocopherolgehalt im Raps und Erstellung von definiertem Ausgangsmaterial. Abschlußbericht zum Teilprojekt 1.4 des vom BMFT geförderten Leitprojekt Ernährung: NAPUS 2000. 
Naczk, M., A. Aramowicz, A. Sullivan and F. Shahidi 1998: Current research developments on polyphenolics of rapeseeds/canola: a review. Food Chemistry 62: 489-502.

Nair, R.B., R.W. Joy, J. Schnaider, E. Kurylo, X. Shi, R.S.S. Datla, W.A. Keller and G. Selvaraj 2000: Identification of a CYP84 family of cytochrome P450- dependent mono-oxygenase genes in Brassica napus and perturbation of their expression for engineering sinapine reduction in the seeds. Plant Physiol. 123: 1623-1634.

Ohlson, R. 1978: Functional properties of rapeseed oil and protein product. In: Proceedings $5^{\text {th }}$ International Rapeseed Congress, pp. 152-167. Malmö, Sweden.

Pokorny, J. and Z. Reblova 1995: Sinapines and other phenolics of Brassicaceae seeds. Potrav. Vedy 13: 155-168.

Reinhardt, T.C. 1992: Entwicklung und Anwendung von Nah-Infrarot-spektroskopischen Methoden für die Bestimmung von Öl-, Protein-, Glucosinolat-, Feuchte- und Fettsäuregehalte in intakter Rapssaat. Dissertation, Universität Göttingen.

Röbbelen, G. 1999: In: BioEngineering für Rapssorten nach Maß. Vorträge für Pflanzenzüchtung 45: 9-27.

Shahidi, F. and M. Naczk 1992: An overview of the phenolics of canola and rapeseed: Chemical, sensory and nutritional significance. J. Am. Oil Chem. Soc. 69: 917-924.

Sozulski, F. 1979: Organoleptic and nutritional effects of phenolic compounds on oilseed protein products: A review. JAOCS 56: 711-715.

Strack, D., W. Knogge and B. Dahlbender 1983: Enzymatic synthesis of sinapine from 10-sinapoylglucose and choline by a cell-free system from developing seeds of red radish (Raphanus sativus L.). Zeitschrift für Naturforschung 38c: 21-27.

Tayaranian, H. R. 1991: Entwicklung eines technischen Verfahrens zur Reduktion von unerwünschten Stoffen (Sinapin und Glucosinolate) in Rapssaat und Rapssaatprodukten der 00-Qualität., Dissertation Christian-Albrechts-Universität zu Kiel

Thies, W. 1991: Determination of the phytic acid and sinapic acid esters in seeds of rapeseed and selection of genotypes with reduced concentrations of these compounds. Fat. Sci. Technol. 93: 49-52.

Thies, W. 1982: Complex formation between glucosinolates and tetrachloropalladate (II) and its utilization in plant breeding. Fette, Seifen, Anstrichmittel 84: 338-342.

Trautwein, E.A. and H.F. Ebersdopler 1998: Rapsöl- ein wertvolles Speiseöl. UFOPSchriften, Heft 6. Union zur Förderung von Oel- und Proteinpflanzen e.V. Bonn.

UFOP, 2004: http: www.ufop.de 
Velasco, L., B. Matthäus and C. Möllers 1998: Nondestructive Assessment of Sinapic Acid Esters in Brassica Species: I. Analysis by Near Infrared Reflectance Spectroscopy. Crop Sci. 38: 1645-1650.

Velasco, L. and C. Möllers 1998: Nondestructive assessment of sinapic acid esters in Brassica species: II. Evaluation of germplasm and identification of phenotypes with reduced levels. Crop Sci. 38: 1650-1654.

Velasco, L., C. Möllers and H.C. Becker 1999: Estimation of seed weight, oil content and fatty acid composition in intact single seeds of rapeseed (Brassica napus L.) by near infrared reflectance spectroscopy. Euphytica 106: 79-85.

Velasco, L. and H.C. Becker 1998: Analysis of total glucosinolate content and individual glucosinolates in Brassica spp. by near-infrared reflectance spectroscopy. Plant Breed. 117: 97-102.

Zukalova, H. and J. Vasak 1999: Natural antioxidants in winter rape (Brassica napus L.). In: Rapskongreß (CD-Rom). Canberra, Australien. 


\section{Manuskript I}

Genetic variation for sinapate ester content in winter rapeseed (Brassica napus L.) and development of NIRS calibration equations 


\title{
Genetic variation for sinapate ester content in winter rapeseed (Brassica napus L.) and development of NIRS calibration equations
}

\begin{abstract}
Increasing the meal and protein quality for food and feed purposes is an important breeding goal for winter rapeseed (Brassica napus L.). Rapeseed meal has a high content of phenolic acid esters, mainly sinapate esters (SE), which have been shown to cause a dark colour and a bitter taste of rapeseed meal and derived protein products. The aim of the present study was to analyse the genetic variation for sinapoylcholine (sinapine), sinapoylglucose and sinapate (including other minor not yet characterized sinapate containing esters, 'other SE'), to develop near infrared reflectance spectroscopical (NIRS) calibration equations for these compounds, and to identify genotypes with a low total SE content after testing in field experiments. A genotypic diverse set of seed samples of winter oilseed rape (old and present cultivars, breeding lines, resynthezised rapeseed) derived from different environments (years and locations) were gradually collected, their NIRS spectra were recorded and the samples were analysed by HPLC. Preliminary calibrations were used to identify additional seed samples with increased variation in SE content and composition. The final NIRS calibration seed sample set $(n=549)$ showed a large variation in total SE content ranging from 2.7 to $13.1 \mathrm{mg}$ sinapate $\mathrm{g}^{-1}$ seeds. Sinapine was with a mean of $65 \%$ of the total SE the predominant component, with a range from $25 \%$ to over $95 \%$. The relative contents of sinapoylglucose and the other SE also showed a large variation. The NIRS calibration equations showed high fractions of explained variances in cross validation $\left(R_{c v}^{2}\right)$ ranging from 0.69 (other SE) over 0.79 (sinapoylglucose) and 0.80 (total SE) to 0.81 (sinapine). The standard errors of cross validation (SECV) ranged from 0.45 (other SE) to $0.77 \mathrm{mg}$ $\mathrm{g}^{-1}$ seed (total SE). The SD/SECV ratio for total SE and sinapine was 2.3, indicating that the calibration equations are useful to identify genotypes with a low SE content in breeding material. Genotypes with a 30-40\% lower total SE content compared to check cultivars have been identified. Low SE contents have been confirmed by HPLC analysis after testing the material in field experiments. The NIRS calibration equations and the identified genotypes low in total SE content could be useful in breeding for reduced sinapate ester contents in rapeseed.
\end{abstract}




\section{INTRODUCTION}

Oil seed rape (Brassica napus) is the most important oil crop in temperate regions of the world and ranks second amongst oilseed crops produced worldwide. Seeds of $B$. napus accumulate oil to about $40-50 \%$ of dry matter. Cultivars strongly reduced in erucic acid and glucosinolates (canola rape, 00 quality) give one of the healthiest vegetable oils for human consumption (Downey and Bell 1990). The meal remaining following oil extraction contains about $40 \%$ protein. The protein fraction is known for its well-balanced amino acid composition (Ohlson 1978) and high biological value (Campbell et al. 1981), making rapeseed protein a possible source for food-grade supplements, a growing market which is so far based mainly on soybean. Unfortunately, the use of rapeseed in human nutrition is still thwarted by the presence of undesirable phenolic compounds. Due to their concentration that is about 30 times higher than in soybean, these compounds remain a principal antinutritive factor in canola seeds (Sosulzki 1979, Ismail et al. 1981, Kozlowska et al. 1990, Shahidi and Naczk 1992).

The predominant phenolic compounds in seeds of oilseed rape are sinapate esters (SE) with sinapoylcholine (sinapine) as the most common one (Kozlowska et al. 1990, Shahidi and Naczk 1992). They make up 1-2 \% of the seed dry matter (Bell 1993) and contribute to the bitter taste, astringency and dark colour of rapeseed products. Being oxidized during seed oil processing, SE may form complexes with proteins, thus lowering the digestibility of rapeseed meal (Kozlowska et al. 1990, Shahidi and Naczk 1992, Naczk et al. 1998). This makes the reduction of SE content a substantial requirement for establishing oilseed rape as a protein crop.

So far, specific breeding programmes aimed at developing rape seed cultivars with low SE content have not yet been set up. Several studies on the genetic variability of SE content in seeds of Brassica ssp. have been carried out (Kerber and Buchloh 1980, Kräling et al. 1991, Bouchereau et al. 1991, Matthäus 1997, Wang et al. 1998). Analysing 1361 samples of rape seed breeding lines, Velasco and Möllers (1998) reported on a range in SE content from 5 to $18 \mathrm{mg} / \mathrm{g}$ seeds. This reported variation was determined by using a less accurate photometric test (Velasco und Möllers 1998) and the results were not confirmed after testing the material in field experiments.

The molecular regulation of sinapate ester biosynthesis and metabolism has been studied in detail (Milkowski et al. 2004 and references therein) and genes of key enzymes of this pathway have been cloned (e.g. Milkowski et al. 2000). Gene technological approaches have resulted in transgenic rapeseed lines with a drastically 
reduced sinapate ester content (Nair 2000, Hüsken et al. 2005a,b).

For the accurate analysis of sinapate ester content and composition usually HPLC is applied. However, for breeding purposes this method has a too low throughput and is much too expensive. Photometric tests (Thies 1991) allow the determination of the total phenolic acid ester content, but are less accurate and still require destructive sample preparation. The application of near infrared reflectance spectroscopy (NIRS) appears here to be the method of choice, because it allows simultaneously to other routinely analysed seed quality traits (Tkachuk 1981, Velasco and Becker 1998, Velasco et al. 1999) the determination of the sinapate ester content; and that in a quick, nondestructive and cost effective way. A first NIRS calibration for the prediction of the total phenolic acid content based on reference values from a photometric test was developed by Velasco et al. (1998).

The objective of the present study was to analyse the genetic variation for SE content and composition in a large germplasm collection using HPLC, to identify genotypes with a low content after testing in the field, and to develop improved near infrared reflectance spectroscopical (NIRS) calibrations to allow an efficient and non-destructive selection in breeding programmes.

\section{MATERIAL AND METHODS}

\section{Field experiments}

A population $(n=70)$ consisting of 16 doubled haploid $(\mathrm{DH})$ lines derived from the cross between a winter rapeseed doubled haploid line derived from the cv. Mansholts' Hamburger Raps x cv. Express, 46 doubled haploid lines of the cross between the winter canola line 'Sva 0565' and a doubled haploid line derived from the cv. Samourai and the parental lines (2x) were tested together with the check cultivars Apex and Mohican. The field experiment was performed in 2001 and 2002 at Göttingen-Reinshof and at Hohenlieth in Northern Germany in a randomized block design with two replicates. At flowering three plants per replication were bagged to secure self pollination.

\section{Prediction of oil, protein and glucosinolate content}

Seed samples were dried and analysed by Near Infrared Reflectance Spectroscopy (NIRS) for their oil, protein and glucosinolate content using the calibration equation 'raps2001.eqa' developed by Tillman (2005). 


\section{Analysis of sinapate esters}

Analysis of seed samples used for the NIRS calibration development was performed at the Institute for Plant Biochemistry (IPB) in Halle/Saale. Grinded seed material (20 mg) was extracted with $1 \mathrm{ml}$ Methanol/ $\mathrm{H}_{2} \mathrm{O}(4: 1)$ in $2 \mathrm{ml}$-safe-lock tubes in the presence of zirconia beads $(1 \mathrm{~mm}$ ) using a bead beater (Bio Spec Products, Inc., Bartlesville, OK, USA). Reversed phase HPLC (Waters Separator 2795, Waters 2996 photodiode array detector and Waters 474 fluorescence detector) was carried out using a Nucleosil $5-\mu \mathrm{m}$ $\mathrm{C}_{18}$ column (250x4 mm i.d., Machery\&Nagel, Düren, Germany). After centrifugation of the extracts $10 \mu \mathrm{l}$ samples were injected. Separation was achieved using a 20-min linear gradient at a flow rate of $1 \mathrm{ml} \mathrm{min}^{-1}$ from 10 to $50 \%$ solvent $B$ (acetonitrile) in solvent $A$ (1.5\% o-phosphoric acid in water). Sinapate esters were analysed using the same method. They were detected at $330 \mathrm{~nm}$ and quantified by external standardization with 1O-ß-D-sinapoylglucose, sinapine and sinapate, respectively. The other minor sinapate esters were identified by their for sinapic acid specific absorption maxima at $240 \mathrm{~nm}$ and $330 \mathrm{~nm}$. The total sinapate ester content (total SE) and the sum of the 'other SE' were calculated as $\mathrm{mg} / \mathrm{g}$ sinapate.

Analysis of seed samples obtained from the field experiments was performed in the Institute of Plant Breeding at the University of Göttingen following the same protocol but using a Gynkotec HPLC and a 5- $\mu \mathrm{m}$ Nucleosil $\mathrm{C}_{18}$ column $(250$ x $3 \mathrm{~mm}$ i.d., MachereyNagel, Düren, Germany). For sinapate ester separation a 20-min linear gradient was applied at a flow rate of $1.2 \mathrm{ml} \mathrm{min}^{-1}$ from 10 to $90 \%$ solvent $B$ (acetonitrile) in solvent $A$ (1,5\% o-phosphoric acid in water). Sinapate, sinapine and sinapoylglucose were detected at $330 \mathrm{~nm}$ and quantified by external standardization with authentic compounds as described above. The other minor sinapate esters were identified by comparing chromatorgrams obtained by the method described above using the PDA detector. Oil, protein, and glucosinolates were determined in whole seed by near-infrared reflectance spectroscopy (NIRS, Tillmann 2005).

\section{NIRS calibration development}

Seed samples used for NIRS calibration development included genotypically divergent winter rapeseed material (breeding lines, resynthezised rapeseed, gene bank material and lines derived from a mutation experiment) cultivated at the experimental station Reinshof near Göttingen in 1997-2000. Samples were also provided by the breeding companies NPZ, Hohenlieth, and DSV, Thüle. Before scanning the sample seeds, they were dried in oven at $65^{\circ} \mathrm{C}$ for $7 \mathrm{~h}$ and afterwards allowed to adjust to room temperature for about 3h. Then they were scanned by NIRS monochromator model 6500 (NIR 
Systems, Inc., Silver Springs, MD) using small ring cups with sample autochanger, and their spectra collected between $400-2500 \mathrm{~nm}$, registering the absorbance values log(1/R) at $2 \mathrm{~nm}$ intervals for each sample. The results of the calibration calculation were checked observing the $t$-ouliers with $t>2.5$. Samples with $t>2.5$ were either re-analysed or deleted from the sample file.

At first a collection of 184 rapeseed samples were scanned by NIRS. Preliminary NIRScalibrations for sinapine, sinapoylglucose, for the sum of the not yet characterized SE and for the total content of SE were developed using the HPLC method for generating reference values. The preliminary NIRS calibrations were used to analyse 10.399 and 11.276 NIRS-spectra of seed samples (Harvest 2001, different locations) provided by the breeding companies NPZ, Hohenlieth, and DSV, Thüle. The spectra provided by the breeding companies were standardized to the NIRS equipment in Göttingen. Additional NIRS spectra from seed samples available in Göttingen ( $n=2549$ from field harvest 1997 - 2000, DH-Populations, resynthesized rapeseed material, the complete winter rapeseed gene bank material of the IPK Gatersleben) were also used to estimate the SE content.

Based on the variation in SE content and composition, geographical origin and spectral divergence additional seed samples were selected and analysed by HPLC. A total of 549 samples were used to develop the final calibration equations for sinapine, sinapoylglucose, the 'other SE' and for the total content of SE ('total SE'). Calibration equations were developed under WinISI II Project Manager v.1.04, with spectral information from 400-2500 $\mathrm{nm}$ and using modified partial least squares (MPLS) regression and cross-validation technique. The derivative and math treatment were 2,5,5,1 for all SE components and for total SE. The first number is the derivative, the second number the gap, and third and fourth numbers are the smooth.

\section{Statistical analysis}

Analysis of variance was performed using the Plant Breeding Statistical Program PLABSTAT), Version 2N (Utz 1997). Considering all factors as random, the following model was used: $Y_{i j k}=\mu+g_{i}+e_{j}+r_{j k}+g e_{i j}+\varepsilon_{i j k}$ with $Y_{i j k}=$ observation of genotype $\mathrm{i}$ in environment $j$ in replication $k, \mu=$ general mean, $g_{i}=$ effect of genotype $i, e_{j}=$ effect of environment $j, r_{j k}=$ effect of replication $k$ in the environment $j, g_{e i j}=$ genotype $\mathrm{x}$ environment interaction of genotype $i$ with environment $j, \varepsilon_{i j k}=$ residual error of genotype $i$ in environment $j$ in replication $k$. 


\section{RESULTS}

The HPLC method allowed the detection of sinapine (sinapoylcholine), sinapoylglucose, and sinapate as well as a number of other not yet characterized sinapate containing compounds. Because the contents of sinapate and the other not yet characterized sinapate containing compounds were minor, they were grouped together ('other SE'). The 549 seed samples selected from different environments for the development of the NIRS calibration equations showed a large variation for each of these constituents (Tab.1).

Tab. 1: Variation, NIRS-calibration and cross validation statistics for the content of sinapate esters (SE, $\mathrm{n}=549$ seed samples)

\begin{tabular}{|c|c|c|c|c|c|c|c|}
\hline \multirow[t]{3}{*}{ Sinapate esters } & & & & \multicolumn{2}{|c|}{$\underline{\text { calibration }}$} & \multicolumn{2}{|c|}{$\underline{\text { cross validation }}$} \\
\hline & mean & SD & range & $\mathrm{R}^{2}{ }_{\mathrm{C}}$ & SEC $^{a}$ & $\mathrm{R}_{\mathrm{cV}}^{2}$ & SECV ${ }^{b}$ \\
\hline & \multicolumn{3}{|c|}{------------(mg/g)---------- } & & $(\mathrm{mg} / \mathrm{g})$ & & $(\mathrm{mg} / \mathrm{g})$ \\
\hline Sinapine & 7.46 & 1.42 & $3.2-11.7$ & 0.86 & 0.54 & 0.81 & 0.62 \\
\hline Sinapoylglucose & 2.10 & 1.47 & $0.0-6.5$ & 0.87 & 0.53 & 0.79 & 0.67 \\
\hline Other SE ${ }^{1}$ & 1.51 & 0.81 & $0.0-3.9$ & 0.76 & 0.40 & 0.69 & 0.45 \\
\hline Total-SE ${ }^{1}$ & 7.89 & 1.73 & $2.7-13.1$ & 0.85 & 0.64 & 0.80 & 0.77 \\
\hline
\end{tabular}

${ }^{1}$ calculated as sinapate, ${ }^{a}$ SEC $=$ standard error of calibration, ${ }^{b}$ SECV $=$ standard error of cross validation, $\mathrm{R}^{2} \mathrm{c}, \mathrm{R}_{\mathrm{cv}}{ }_{\mathrm{c}}=$ explained fraction of variance in calibration and in cross validation, respectively

With a mean of $7.46 \mathrm{mg} / \mathrm{g}$ sinapine was the most prominent SE, followed by sinapoylglucose and the other SE. The total SE content showed a large variation from 2.7 - $13.1 \mathrm{mg} / \mathrm{g}$ sinapate. A similiar large variation was found for sinapine, sinapoylglucose and the other SE. Noticeably, samples were identified, which did not contain any sinapoylglucose or any of the other SE.

The large variation in the SE composition is shown in Fig.1. It can be seen that the sinapine content ranges from $25 \%$ to over $95 \%$ of the total SE. Most of the genotypes have a sinapine content of around $65 \%$. Sinapoylglucose ranges from $0 \%$ to $50 \%$ of the total SE, with a mean of $25 \%$. There is quite a large number of samples with no or a very little content of the other SE. However, samples with an up to $45 \%$ contribution of the other SE to the total SE were also identified. 


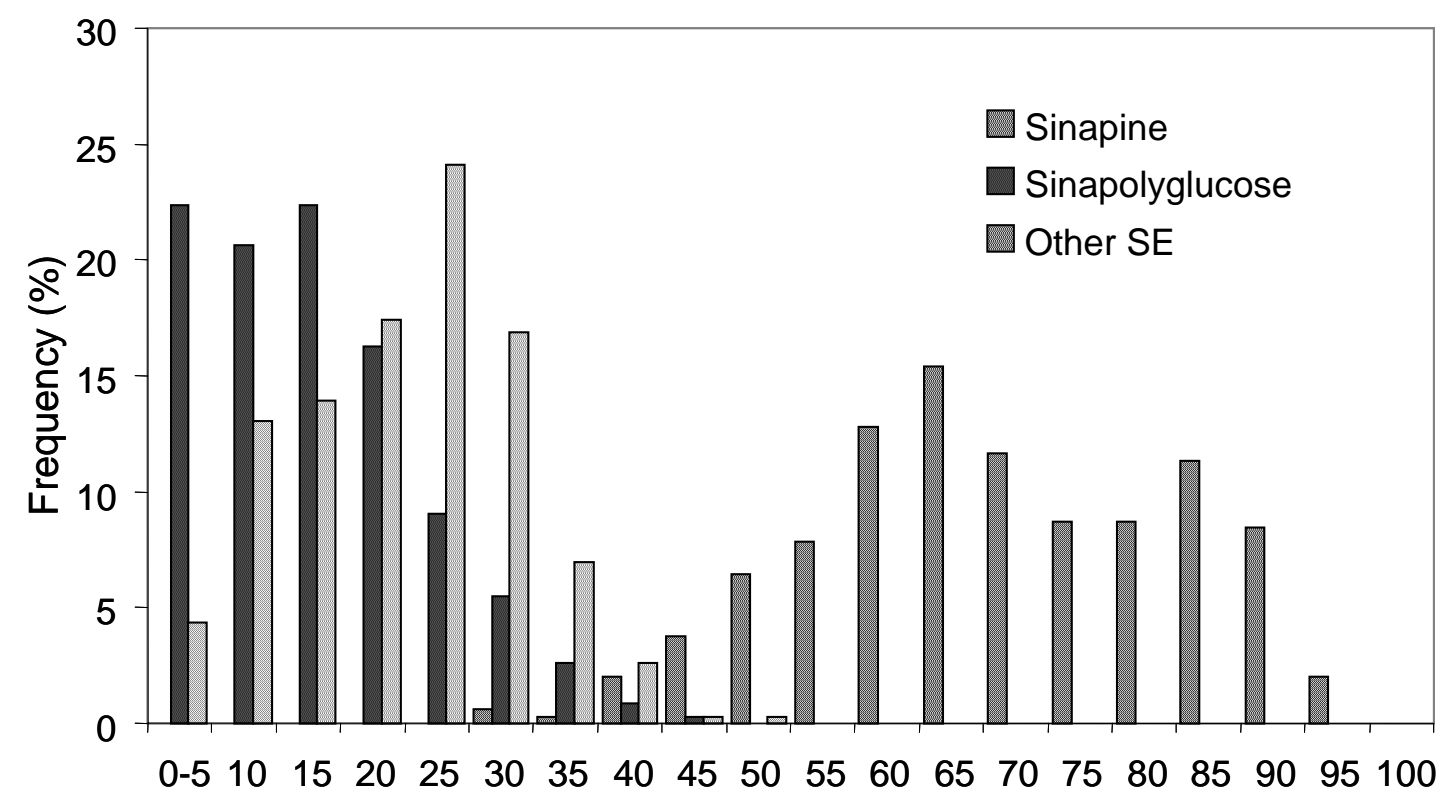

$(\%)$

Fig. 1: Frequency distribution (\%) of genotypes with varying contents (\% of total SE) of sinapine, sinapoylglucose and other SE $(n=549)$

The NIRS calibration equations developed on the basis of the 549 selected rapeseed samples showed high fractions of explained variance $R^{2}$ (Tab. 1). The fractions of explained variance in cross-validation, $\mathrm{R}^{2}{ }_{\mathrm{cv}}$, were somewhat lower. The standard errors of calibration (SEC) and the standard errors in cross validation (SECV) were quite low for sinapine and total SE (SECV/Mean $=8 \%$ and 10\%) but higher for sinapoylglucose $($ SECV/Mean $=32 \%)$ and the other SE $($ SECV/Mean $=30 \%)$. The SD/SECV ratio was highest for Sinapine and total SE (2.3), followed by sinapoylglucose (2.2) and by the other SE (1.8). As an example, the calibration plot for the total SE is shown in Fig. 2. 


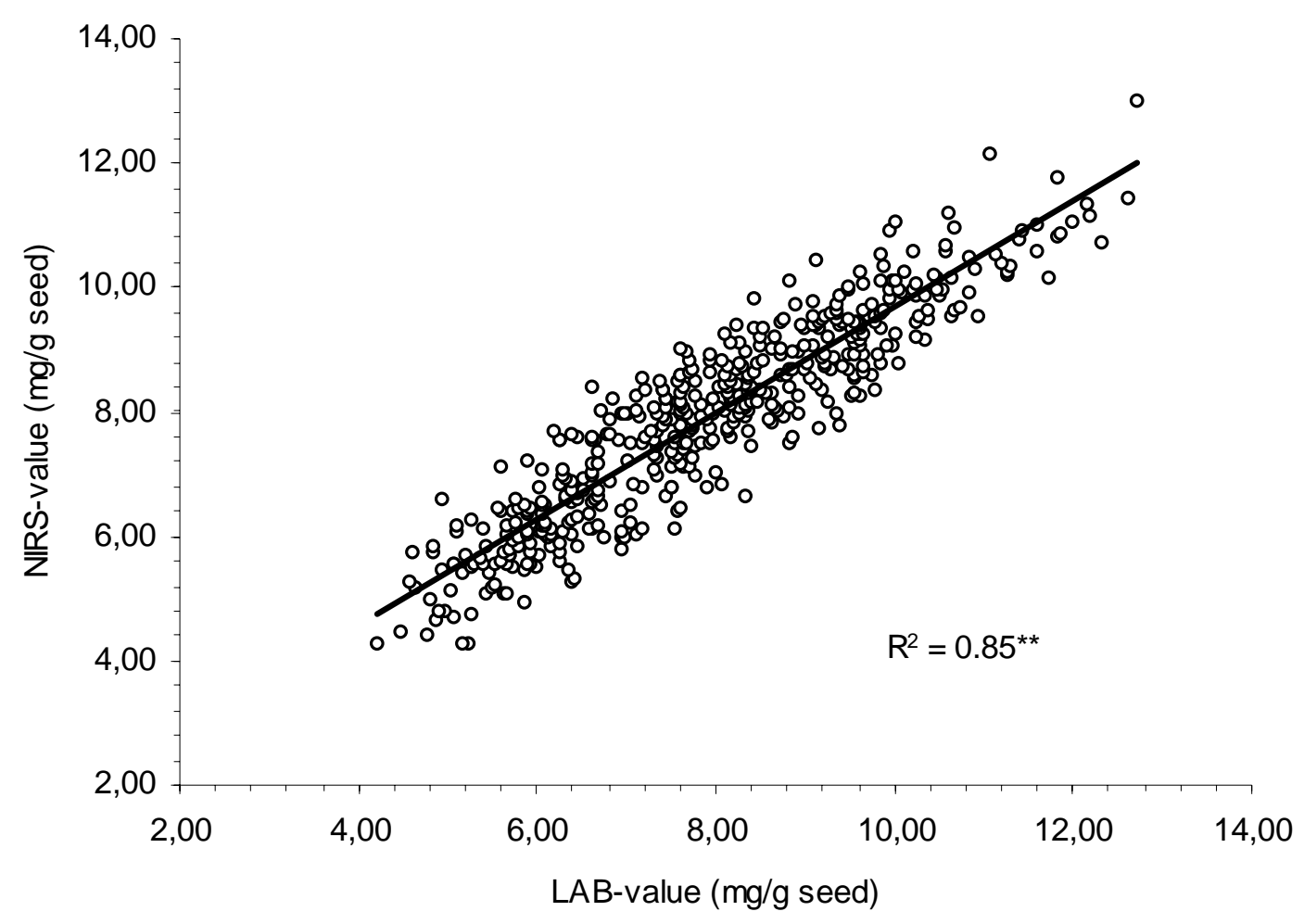

Fig. 2: NIRS calibration plot for the total sinapate ester content of the seed samples used for calibration development $(n=549)$ as determined by HPLC and as predicted by NIRS

In the calibration sample set, the contents of sinapoylglucose, sinapine and the other SE were significantly positive correlated with total SE (Tab. 2). Sinapoylglucose was negatively correlated with sinapine, but positively correlated with the other SE. The total SE was at a low level positively correlated with the oil content and negatively correlated with the protein and glucosinolate content.

Tab. 2: Spearman rank correlations for the sinapate esters (SE) and the oil, protein and glucosinolate contents in the calibration set of $n=549$ seed samples

\begin{tabular}{|c|c|c|c|c|c|c|}
\hline Sinapoylglucose & $-0.24^{\star \star}$ & & & & & \\
\hline Other SE & 0.04 & $0.67^{* \star}$ & & & & \\
\hline Total-SE & 0.40 ** & 0.69 ** & $0.84^{\star \star}$ & & & \\
\hline Oil & -0.07 & $0.26^{\star *}$ & $0.09 *$ & $0.13^{* *}$ & & \\
\hline Protein & $0.29 * \star$ & $-0.54^{\star \star}$ & $-0.33^{\star *}$ & $-0.26^{\star *}$ & $-0.79^{\star *}$ & \\
\hline \multirow[t]{2}{*}{ Glucosinolates } & 0.39 ** & $-0.55^{\star \star}$ & $-0.49 * \star$ & $-0.29^{\star *}$ & $-0.21^{\star *}$ & $0.42^{\star *}$ \\
\hline & Sinapine & $\begin{array}{l}\text { Sinapoyl- } \\
\text { glucose }\end{array}$ & Other SE & $\begin{array}{l}\text { Total- } \\
\text { SE }\end{array}$ & Oil & Protein \\
\hline
\end{tabular}

${ }^{*},{ }^{* *}$ significant at $p<0.05$ and $p<0.01$ 
The developed calibration equations were used to predict the SE content of additional 24.224 seed samples (Tab. 3). A big range in total SE content as well as in the individual SE were detected among these samples, which however, did not reveal samples with a lower content than detected before. The means and ranges were quite similar for the material from the breeding companies NPZ and DSV and for the material from the University of Göttingen.

Tab. 3: Variation in the SE-content of seed samples following analysis with NIRS

\begin{tabular}{lcccccc}
\hline & \multicolumn{2}{c}{ NPZ $(\mathrm{n}=10399)$} & \multicolumn{2}{c}{$\mathrm{DSV}(\mathrm{n}=11276)$} & \multicolumn{2}{c}{ Göttingen $(\mathrm{n}=2549)$} \\
& range & mean & range & mean & Range & mean \\
\hline Sinapine & $3.1-10.5$ & 6.7 & $2.5-13.5$ & 6.7 & $3.8-13.3$ & 8.2 \\
Sinapoylglucose & $1.2-5.4$ & 3.1 & $0.0-5.6$ & 3.0 & $0.0-5.8$ & 2.4 \\
Other SE $^{1}$ & $0.4-3.9$ & 1.4 & $0.3-4.0$ & 1.4 & $0.4-4.2$ & 1.5 \\
Total-SE $^{1}$ & $4.0-12.6$ & 8.1 & $4.3-14.3$ & 7.9 & $4.1-13.8$ & 8.9 \\
\hline
\end{tabular}

${ }^{1}$ calculated as sinapate, $\mathrm{n}=$ number of seed samples, all values in $\mathrm{mg} / \mathrm{g}$ seeds

Doubled haploid lines with a very low and very high content of SE were selected and tested in a field experiment. The results obtained showed significant genotypic differences and partly confirmed the large variation found in the original seed samples (Tab. 4). The variation in total SE ranged from 4.86 to $9.17 \mathrm{mg} / \mathrm{g}$ seeds (1.9 fold). Among those lines, a lower variation was found for sinapine (1.5 fold) and a much larger variation was found for sinapoylglucose ( 7.9 fold) and the other SE (9.9 fold). DH lines from the cross DH Mansholts' $x$ Express including the parent DH Mansholts' turned out to belong to those with the lowest total SE contents among all lines tested in different field experiments (data not shown). $\mathrm{DH}$ Mansholts and some related $\mathrm{DH}$-lines showed to contain $30-40 \%$ less SE than the cultivars Express, Apex, Mohican and DH Samourai. The cultivar Mohican surprised with relatively low sinapine contents and relative high contents of sinapoylglucose and of the other SE. 
Tab. 4: Variation for sinapate esters (SE in $\mathrm{mg} / \mathrm{g}$ ) in a set of 70 doubled haploid canola lines, which were tested in field experiments. The results of the five genotypes with the lowest SE and of the three genotypes with the highest SE content are shown. Data represent means from 4 environments with each 2 replicates.

\begin{tabular}{lcccc}
\hline Genotype & Sinapine & Sinapoylglucose & Other SE & Total-SE $^{1}$ \\
\hline DH 41 MxE & 6.20 & 0.54 & 0.33 & 4.86 \\
DH Mansholts & 6.96 & 0.50 & 0.22 & 5.24 \\
DH 62 MxE & 6.20 & 0.87 & 0.55 & 5.27 \\
DH 99 MxE & 6.44 & 0.75 & 0.50 & 5.31 \\
DH 217 MxE & 7.02 & 0.79 & 0.46 & 5.69 \\
DH 44 SxS & 6.80 & 3.29 & 2.04 & 8.57 \\
DH 41 SxS & 7.62 & 3.12 & 1.84 & 8.83 \\
DH 47 SxS & 7.50 & 3.27 & 2.17 & 9.17 \\
Sv0565 & 6.35 & 2.37 & 1.47 & 7.16 \\
Express & 6.94 & 2.21 & 1.49 & 7.49 \\
Apex & 6.33 & 2.68 & 1.66 & 7.52 \\
Mohican & 4.98 & 3.93 & 2.47 & 8.14 \\
DH Samourai & 7.06 & 2.82 & 1.76 & 8.20 \\
\hline Min & 4.98 & 0.50 & 0.22 & 4.86 \\
Max & 7.62 & 3.93 & 2.47 & 9.17 \\
Mean & 6.69 & 2.41 & 1.49 & 7.43 \\
\hline LSD 5\% & 0.71 & 0.47 & 0.29 & 0.65 \\
\hline
\end{tabular}

${ }^{1}$ calculated as sinapate 


\section{DISCUSSION}

The results of the present study show a considerable variation in sinapate ester (SE) content and composition in a set of seed samples, which were selected from a large genotypic diverse collection harvested in different years. The total SE content ranged from 2.7 to $13.1 \mathrm{mg}$ sinapate $\mathrm{g}^{-1}$ seeds, which is equivalent to 12 to $58 \mu \mathrm{mol} \mathrm{g} \mathrm{g}^{-1}$ seeds.

Velasco and Möllers (1998) reported on a range in SE content from 5 to $18 \mathrm{mg} / \mathrm{g}$ seeds analysing 1361 samples of rapeseed breeding lines. However, they did use a less accurate photometric assay to determine the total phenolic acid ester content, which may include also other less prominent phenolic acids and their esters, present in the seeds of oilseed rape (Mabon et al. 1999). The photometric assay did not allow a separate quantification of sinapate and the different esters as it was possible in the present study. Boucherau et al. (1991) analysed by HPLC 202 different rapeseed types (winter and spring types, oil and forage types, $B$. napus var. rapifera Metzg.) and found a variation of 24.9 to $47.4 \mu \mathrm{mol}$, eq sinapine $\mathrm{g}^{-1}$ dry seeds, which is considerably less than the 12 to 58 $\mu \mathrm{mol} \mathrm{g} \mathrm{g}^{-1}$ sinapate found in the present study. Analysing a broad spectrum of rapeseed lines $(n=42)$ as well as resynthesized genotypes $(n=98)$ during three years in the field, Kräling et al. (1991) reported a variation in total SE content between 17.8 and $71.9 \mu \mathrm{mol}$ $\mathrm{g}^{-1}$ defatted seed meal, applying a photometric assay. Because the basis is defatted seed meal', these values are difficult to compare. However, noticeably Kräling et al. (1991) reported that the resynthesized lines did reveal an even smaller variation in total SE than the rapeseed lines. This was confirmed in the present study in which the resynthesized material did not show any striking variation.

Sinapine has been reported to be with $70 \%$ of the total SE the predominant SE component in rapeseed (Bouchereau et al. 1991, Kolodziejczyk et al. 1999). This is in accordance with the $65 \%$ found in the present study. However, Fig. 1 shows a considerable variation in the SAE composition among the samples and the sinapine content ranges from about $25 \%$ to over $95 \%$ of total SAE content. A similar large variation was found for sinapoylglucose and the other SE. These results are difficult to compare with results from the literature, because so far the complete sinapate ester composition has not been reported for a larger germplasm collection. It can also be expected, that the variation found in the present study will be less after testing the material in multiple environments (see discussion below).

At the beginning of the present study, the NIRS calibration equation developed by Velasco et al. (1998) was used to identify seed samples low and high in total SE. 
However, the correlation to results obtained by HPLC was not satisfactory (data not shown). This may be explained by the fact that Velasco et al. (1998) used a less accurate photometric test for total SE determination. This test may also be less specific and detect other phenolic acids and their esters present in seeds of oilseed rape. Hence, it was decided to develop new NIRS calibrations for individual and total sinapate esters based on HPLC analytics. The developed NIRS calibration equation for sinapine, sinapoylglucose, other SE and total SE showed fractions of explained variances in cross validation $\left(R^{2}{ }_{c v}\right)$ ranging from 0.69 (other $S E$ ) to 0.81 (sinapine). The somewhat lower $\mathrm{R}^{2}{ }_{\mathrm{cv}}$ in comparison to $\mathrm{R}^{2}$ indicates that the calibration set is not homogenous and could be improved by adding spectra and reference values from additional seed samples. Those samples should not only show a larger variation for the different SE, but should also be taken from different locations and harvest years, to make the calibration equation less sensitive towards environmental effects. The standard errors of cross validation (SECV) were in the range of 0.45 (other SE) to 0.77 (total SE). For the relatively high SECV in relation to the mean values of sinapoylglucose and the other SE, we have at present no ready explanation. A small size of the standard error SECV alone does not clearly reflect the usefulness of a NIRS calibration in breeding programs. If the ratio of the standard deviation SD of the sinapate ester in the sample population to the SECV is calculated, a clearer picture appears. If the SD/SECV ratio is high, NIRS predictions enable one to significantly divide a given amount of samples in some subgroups of low, medium, and high contents of the sinapate esters. According to Fontaine et al. (2001) a calibration equation is very meaningful to predict a trait if this ratio exceeds a value of 3 , whereas in the case of values below 2, the applicability is limited. In the present study the SD/SECV ratio was in the range of 1.8 (other SE) to 2.2/2.3 for sinapoylglucose, total SE and sinapine, indicating its usefulness to identify genotypes with a low total SE content in breeding programs. An independent and external validation with seed samples from years and environments not considered in the calibrations have in principal confirmed the possibility to identify genotypes with a low total sinapate ester content. These data are not shown here, because the result may be different depending on the environment from which the seed samples are derived and on the genotypic composition of randomly selected seed samples used for validation (range and SD of the individual and total sinapate ester content). A simple way to improve the NIRS calibrations could be the inclusion of seed samples from transgenic rapeseed plants which have been shown to have a drastically reduced content of sinapate esters (Nair et al. 2000, Hüsken et al. 2005a, Hüsken et al. 2005b).

The developed NIRS calibration equations have been transferred to the plant breeding companies Norddeutsche Pflanzenzucht (NPZ), Hohenlieth, and Deutsche 
Saatveredlung (DSV), Lippstadt, and have been implemented in their NIRS seed quality analysis procedure. Thus, data for sinapate ester content of breeding material is simultaneously and in a non-destructive way obtained together with the oil, protein, glucosinolate and fatty acid content. However, the prediction of sinapate ester content from NIRS spectra from seed samples of the harvest 2001 provided by the breeding companies (Tab. 3) did not reveal genotypes with sinapate ester contents which goes beyond that present in the calibration collection, following HPLC confirmation (data not shown).

\section{Correlation among sinapate esters and with other traits}

An important consideration while screening for reduced levels of a quality trait is the simultaneous variation in economically relevant traits. The present results show a positive correlation between total SE content and oil content and a negative correlation with protein and glucosinolate. The coefficients of correlation were highly significant. For oil and protein content the coefficients were similar to those obtained by Velasco and Möllers (1998) for a set of 1361 B. napus seed samples, whereas they did not find any significant correlation to glucosinolate content. Correlations may be very much artificially influenced by the composition of a genotype collection and by environmental influences on the analysed seed material. To obtain meaningful genetic correlations among traits, segregating populations derived from a cross between parental lines need to be analysed (Zum Felde 2005). However, the present data also show that there is a positive correlation between the individual SE and the total SE content. This indicates that selection for a low total SE content will result in the reduction of all SE components.

\section{Identification of genotypes with a low total SE ester content}

The screening of the large number of seed samples described above, revealed genotypes with a comparatively low and high content of sinapate esters. However, after testing those genotypes in the field, usually the extreme contents could not be confirmed (data not shown). This indicated that sinapate ester content is influenced by environmental conditions. Bouchereau et al. (1996) found that water stress during early vegetative growth reduced seed sinapine content by about $30-40 \%$, whereas water stress at flowering time enhanced sinapine content. Nonetheless, a few genotypes with a low total SE content were identified in the present study. Among those were a doubled haploid line obtained from the old cultivar Mansholts' Hamburger Raps which was tested during two years at two locations in the field. The results confirmed for DH Mansholts' and some related DH lines their low total SE content, in comparison to the cvs. Express, Apex, Mohican, Samourai (DH) and the breeding line Sv0565 (Tab. 4). 


\section{Breeding implications}

A breeding for reduced contents of sinapic acid esters has so far not been performed. With the availability of the NIRS calibrations a well-aimed crossing between genotypes with low contents of individual sinapate esters and with overall low contents can be performed and offsprings with further reduced contents may be identified. In this regard, the $\mathrm{cv}$. Mohican may be interesting, because it showed a particulary low sinapine content (Tab. 4). Additional genetic variation may be found by screening a larger germplasm collection or by analysing the genetic variation available in the two diploid ancestor species of rapeseed, B. rapa and B. oleracea. Comparing these two species, Bouchereau et al. (1991) found that $B$. rapa accessions contained considerable less phenolic choline esters in the seeds than $B$. oleracea accessions. $B$. napus accessions had intermediate contents. Additional variation found in the two diploid species can be used for rapeseed quality improvement by resynthesizing rapeseed (Chen and Heneen 1989). The NIRS calibrations may also be used to screen in an efficient and nondestructive way seed samples derived from mutation experiments performed in rapeseed but also in the diploid ancestor species B. rapa and B. oleracea. Crossing of conventional low SE genotypes with transgenic lines (Nair et al. 2000, Hüsken et al. $2005 a, b)$ showing overall low contents of SE may be performed to identify recombinants with an even further reduced total SE content. However, at present it is unclear if the reductions in total SE content so far achieved result in a significant improvement of rapeseed protein quality, or if the contents have to be further reduced.

\section{ACKNOWLEDGEMENT}

The authors are grateful to Dr. Alfred Baumert (IPB Halle/Saale) for the analysis of sinapate esters in seed samples used for NIRS calibration and for providing his HPLC protocol, HPLC standards and for providing a HPLC-chromatogram that allowed peak identification of the 'other SE'. The authors are indebt to Nicole Ritgen-Homayounfar for technical assistance, to Norddeutsche Pflanzenzucht Hans-Georg Lembke KG (NPZ), Hohenlieth, and Deutsche Saatveredlung (DSV), Lippstadt, for providing NIRS spectra and seed samples. This work is part of the research project "NAPUS 2000-Healthy Food from Transgenic Rape Seeds" and the financial support provided by the Bundesministerium für Bildung und Forschung (BMBF) is gratefully acknowledged. 


\section{REFERENCES}

Bell, J.M., 1993: Factors affecting the nutritional value of canola meal. A review. Can. J. Anim. Sci. 73: 679-697.

Bouchereau, A., J. Hamelin, I. Lamour, M. Renard and F. Larher 1991: Distribution of sinapine and related compounds in seeds of Brassica and allied Genera. Phytochemistry 30: 1873-1881.

Bouchereau, A., N. Clossais-Besnard, A. Bensaud, L. Leport and M. Renard 1996: Water stress effects on rapeseed quality. Eur. J. Agron. 5: 19-30.

Campbell, L.D., B.O. Eggum and I. Jacobsen 1981: Biological value, amino acid availability and true metabolizable energy of low-glucosinolate rapeseed meal (canola) determined with rats and/or roosters. Nutrition Reports International 24: 791-797.

Chen, B.Y. and W. Heneen 1989: Resynthesized Brassica napus L. A review of its potential in breeding and genetic analysis. Hereditas 111: 255-263.

Downey, R.K. and J.M. Bell 1990: New development in canola research, pp. 37-46. In F. Shahidi (Ed.): Canola and Rapeseed. Production, Chemistry, Nutrition and Processing Technology, pp. 211-220. Van Nostrand Reinhold, New York.

Fontaine, J., J. Hörr and B. Schirmer 2001: Near-infrared reflectance spectroscopy enables the fast and accurate prediction of the essential amino acid contents in soy, rapeseed meal, sunflower meal, peas, fishmeal, meat meal products, and poultry meal. J Agric Food Chem 49: 57-66.

Hüsken, A., A. Baumert, C. Milkowski, H.C. Becker, D. Strack and C. Möllers 2005a: Resveratrol glucoside (Piceid) synthesis in seeds of transgenic oilseed rape (Brassica napus L.). Theor. Appl. Genet.: DOI 10.1007/s00122-005-0085-1

Hüsken, A., A. Baumert, D. Strack, H.C. Becker, C. Möllers and C. Milkowski 2005b: Reduction of sinapate ester content in transgenic oilseed rape (Brassica napus) by dsRNAi-based suppression of BnSGT1 gene expression. Mol. Breed, in press.

Ismail, F., M. Vaisey-Genser and B. Fyfe 1981: Bitterness and astringency of sinapine and its components. Journal of Food Science 46: 1241-1244.

Kerber, E. and G. Buchloh 1980: Der Sinapingehalt in Cruciferensamen. Angewandte Botanik 54: 47-54.

Kolodziejczyk, P., W. Xiaoyan, M. Marianchuk, L. Wanli and R. Amarowicz 1999: Phenolics In Rapeseed: Capillary Electrophoresis as a novel analytical method for detection of sinapine, sinapic acid esters and ferulates. $10^{\text {th }}$ International Rapeseed 


\section{Congress, Canberra}

Kozlowska, H., M. Naczk, F. Shahidi and R. Zadernowski 1990: Phenolic acids and tannins in rapeseed and canola, pp. 193-210. In: Shahidi, F. (Ed.), Canola and Rapeseed. Production, Chemistry, Nutrition and Processing Technology. Van Nostrand Reinhold, New York.

Kräling, K., G. Röbbelen and W. Thies 1991: Genetic variation of the content of sinapoyl esters in seeds of rape, B. napus. Plant Breeding 106: 254-257.

Mabon, N., J.-P. Wathelet and M. Marlier 1999: Measurement of aromatic choline esters in rapeseed by HPLC. Proceedings of the 10th International Rapeseed Congress Canberra, Australia.

www.regional.org.au/au/gcirc/1/187.htm?PHPSESSID=f4d0c882f8aba705c08f80d82 0316a72\#TopOfPage. Site last visited on september 24, 2005

Matthäus, B. 1997: Antinutritive compounds in different oilseeds. Fett/Lipid 99: 170-174.

Milkowski, C., A. Baumert and D. Strack 2000: Cloning and heterologous expression of a rape cDNA encoding UDP-glucose:sinapate glucosyltransferase. Planta 211: 883886.

Milkowski, C., A. Baumert, D. Schmidt, L. Nehlin and D. Strack 2004: Molecular regulation of sinapate ester metabolism in Brassica napus: expression of genes, properties of the encoded proteins and correlation of enzyme activities with metabolite accumulation. Plant J. 38: 80-92.

Naczk, M., A. Aramowicz, A. Sullivan and F. Shahidi 1998: Current research developments on polyphenolics of rapeseeds/canola: a review. Food Chemistry 62: 489-502.

Nair, R.B., R.W. Joy, J. Schnaider, E. Kurylo, X. Shi, R.S.S. Datla, W.A. Keller and G. Selvaraj 2000: Identification of a CYP84 family of cytochrome P450- dependent mono-oxygenase genes in Brassica napus and perturbation of their expression for engineering sinapine reduction in the seeds. Plant Physiol. 123: 1623-1634.

Ohlson, R. 1978: Functional properties of rapeseed oil and protein product. In: Proceedings $5^{\text {th }}$ International Rapeseed Congress, pp. 152-167. Malmö, Sweden.

Shahidi, F. and M. Naczk 1992: An overview of the phenolics of canola and rapeseed: Chemical, sensory and nutritional significance. J. Am. Oil Chem. Soc. 69: 917-924.

Sozulski, F. 1979: Organoleptic and nutritional effects of phenolic compounds on oilseed protein products: A review. JAOCS 56: 711-715.

Tillmann, P. www.nirs.de Site last visited on september 26, 2005

Thies, W. 1991: Determination of the phytic acid and sinapic acid esters in seeds of 
rapeseed and selection of genotypes with reduced concentrations of these compounds. Fat. Sci. Technol. 93: 49-52.

Tkachuk, R. 1981: Oil and Protein Analysis of Whole Rapeseed Kernels by Near Infrared Reflectance Spectroscopy. J. Am. Oil Chem. Soc. 58: 819-822.

Utz, F. 1997: Plabstat, ein Computerprogramm für statistische Analysen von Pflanzenzüchtungsexperimenten. Universität Hohenheim.

Velasco, L. and H.C. Becker 1998: Analysis of total glucosinolate content and individual glucosinolates in Brassica spp. by near-infrared reflectance spectroscopy. Plant Breed. 117: 97-102.

Velasco, L., B. Matthäus and C. Möllers 1998: Nondestructive Assessment of Sinapic Acid Esters in Brassica Species: I. Analysis by Near Infrared Reflectance Spectroscopy. Crop Sci. 38: 1645-1650.

Velasco, L. and C. Möllers 1998: Nondestructive assessment of sinapic acid esters in Brassica species: II. Evaluation of germplasm and identification of phenotypes with reduced levels. Crop Sci. 38: 1650-1654.

Velasco, L., C. Möllers and H.C. Becker 1999: Estimation of seed weight, oil content and fatty acid composition in intact single seeds of rapeseed (Brassica napus L.) by near infrared reflectance spectroscopy. Euphytica 106: 79-85.

Wang, S., B.D. Oomah, D.I. McGregor and R.K. Downey 1998: Genetic and seasonal variation in the sinapine content of seed from Brassica and Sinapis species. Can. J. Plant Sci. 78: 395-400.

Zum Felde, T. 2005: Genotype x Environment interactions, heritability and trait correlations of sinapate esters in winter rapeseed (Brassica napus L.). Manuscript II in this thesis. 


\section{Manuskript II}

Genotype x Environment interactions, heritability and trait correlations of sinapate ester content in winter rapeseed (Brassica napus L.) 


\title{
Genotype x Environment interactions, heritability and trait correlations of sinapate ester content in winter rapeseed (Brassica napus L.)
}

\begin{abstract}
Increasing the meal and protein quality for food and feed purposes is an important breeding goal for winter rapeseed (Brassica napus L.). The phenolic acid ester content in rapeseed has been reported to be about 30 times higher compared to soybean. They are predominantly sinapate esters (SE) and make up 1-2\% of the seed dry matter and contribute to the bitter taste, astringency and dark colour of rapeseed products. The objective of the present study was to analyse the genotype $x$ environment interactions for SE content and composition in three populations of doubled haploid lines of oilseed rape and to analyse correlations to agronomically relevant seed quality traits. By applying HPLC analytics the following SE could be identified: sinapoylcholine (sinapine), sinapoylglucose, sinapate and other minor sinapate containing esters. Sinapate and the other minor sinapate esters were grouped together to 'other SE'. The three doubled haploid populations showed a highly significant variation for the total SE content, and sinapine showed to be the predominant sinapate ester compound (range of population means: 58\%-72\%). The mean sinapoylglucose content contributed between $17 \%$ and $20 \%$ to the total SE content. The other SE content accounted for $10 \%$ to $22 \%$ of the total SE content in the three populations. The analysis of variance showed highly significant effects for the genotype, the environment and the genoytpe $x$ environment (GxE) interactions for all three populations. The heritabilities for the individual and total SE were generally high and ranged from 0.57 to 0.93 . The total SE content was highly significantly positively correlated with the contents of the individual SE constituents, indicating that reductions in total SE can be achieved by selecting for low contents of either one of the different compounds. No significant correlations between the total SE content and the oil, protein and glucosinolate content were found. In conclusion, the results show that an effective selection for low sinapate ester genotypes should be possible with a comparatively low effort with respect to number of required test environments, provided the breeding material shows a sufficiently high genotypic variation. No evidence was found that a reduction of sinapate ester content coincides with a change in other relevant seed quality traits.
\end{abstract}




\section{INTRODUCTION}

Oil seed rape (Brassica napus) is the most important oil crop in temperate regions of the world and ranks second amongst oilseed crops produced worldwide. Besides being cultivated for its high oil content, the oil extracted meal is a valuable feed stuff. It contains up to $40 \%$ protein, which has a well-balanced amino acid composition (Ohlson 1978) and high biological value (Campbell et al. 1981). Since the worldwide demand for food grade vegetable proteins is steadily increasing, attempts to improve the quality of the rapeseed protein have been started (Leckband et al. 2002). Soybean derived proteins are currently dominating the food market, and any other vegetable protein has to meet existing quality standards to achieve a significant market share. Attempts to use rapeseed proteins in food production has been limited by the presence of undesirable compounds, like glucosinolates, tannins of the black seed coat and phenolic acid esters. The seed glucosinolate content has been drastically reduced to contents of $10 \mu \mathrm{mol} \mathrm{g} \mathrm{g}^{-1}$ seed and below (Raney 1999) by conventional plant breeding taking advantage of spontaneously arisen mutants. Oilseed rape lines with a yellow seed coat have also been developed and are currently used in breeding programmes to develop competitive yellow seeded Brassica napus cultivars (Rahman 2001). Compared to these achievements little has been done to reduce the phenolic acid ester content in rapeseed, which has been reported to be about 30 times higher than in soybean (Sosulzki 1979, Ismail et al. 1981, Kozlowska et al. 1990, Shahidi and Naczk 1992).

The phenolic compounds in canola seeds are predominantly sinapate esters. The most prominent one is the ester sinapoylcholine (sinapine) followed by sinapoylglucose. Minor contents are reported for sinapate and other sinapate esters (Kozlowska et al. 1990, Shahidi and Naczk 1992). Sinapic acid and the derived esters make up 1-2 \% of the seed dry matter (Bell 1993) and contribute to the bitter taste, astringency and dark colour of rapeseed products. Being oxidized during seed oil processing, sinapate esters may form complexes with proteins, thus lowering the digestibility of rapeseed meal (Kozlowska et al. 1990, Shahidi and Naczk 1992, Naczk et al. 1998). This indicates that the reduction of sinapate ester content could be a substantial requirement for establishing oilseed rape as a source for food grade protein. Specific breeding programmes aimed at developing canola cultivars with low sinapate ester content have so far not yet been started. However, several studies report on the existence of a large genetic variability of sinapate ester content and composition in seeds of Brassica napus (Kerber and Buchloh 1980, Kozlowska et al. 1983, Kräling et al. 1991, Bouchereau et al. 1991, Matthäus 1997, Wang et al. 1998, Velasco and Möllers 1998, Zum Felde 2005). More recently transgenic approaches have been successful to decrease the sinapate 
ester content much below the naturally found levels (Nair et al. 2000, Hüsken et al. $2005 a, b)$. With the development of near infrared reflectance spectroscopical (NIRS) calibration equations (Velasco et al. 1998, Zum Felde 2005) an efficient and nondestructive tool for the identification of genotypes with a low sinapate ester content in breeding programs is available. However, so far very little is known about the genotype $x$ environment interactions and the correlation to other agronomically important seed quality traits. The objective of the present study was to analyse the genotype $x$ environment interactions for sinapate ester content and composition in three populations of doubled haploid lines of oilseed rape and to analyse correlations to agronomically relevant seed quality traits.

\section{MATERIAL AND METHODS}

\section{Plant material and field experiments}

Three doubled haploid populations of winter rapeseed were tested in different years and at different locations. Population I consisted of 144 doubled haploid lines derived from the cross between doubled haploid lines of the two rapeseed cultivars, Mansholt's Hamburger Raps and Samourai (Uzunova et al. 1995, Gül 2002), and the parental lines. Population I was grown at two locations in 1999 and 2000 in a randomized block design with two replicates. In 1999, the two locations were two fields at Reinshof (4 km south of Göttingen, Germany), in 2000, one location was Reinshof, the other was Weende (5 km northwest of Göttingen). Population II consisted of 49 doubled haploid lines from the cross between the high oleic acid mutant line 19508 and the low linolenic acid line 2293E. Population II was tested in 2000 at Hohenlieth (located in Northern Germany), Reinshof, and Weende in a randomized block design with three replicates. Population III consisted of 46 doubled haploid lines derived from the cross between the winter canola line 'Sva 0565' and a doubled haploid line derived from the cv. Samourai. Population III was tested in 2001 and 2002 at Reinshof and at Hohenlieth in a randomized block design with two replicates. In population I, seeds from three open pollinated plants were harvested, in Populations II and III, three plants/plot were selfed. Seeds of the plants were bulked for analysis. The seed material of population I and II was provided by Dr. Kemal Gül and Dr. Antje Schierholt, respectively, both University of Göttingen. 
Analysis of sinapate and sinapate esters

The method applied for the analysis of sinapate and sinapate esters was based on the one published by Zum Felde (2005). The two major sinapate esters from seeds, sinapoylglucose and sinapoylcholine (sinapine), and sinapate were identified by chromatographic (HPLC) comparison with standard compounds. Seed material $(20 \mathrm{mg}$ ) was extracted with $400 \mu \mathrm{l}$ of a methanol-water mixture (4:1) in $2 \mathrm{ml}$-safe-lock tubes by vigorous shaking in the presence of zirconia beads ( $1 \mathrm{~mm}$ in diameter) using a bead beater (Bio Spec Products, Bartlesville, OK, USA). The resulting homogenates were cleared by centrifugation and aliquots of the supernatants transferred into HPLC autosampler vials. Reversed phase HPLC (Gynkotec HPLC with UV-detector) was carried out using a 5- $\mu \mathrm{m}$ Nucleosil $\mathrm{C}_{18}$ column (250 x 3 mm i.d., Macherey-Nagel, Düren, Germany). A 20-min linear gradient was applied at a flow rate of $1.2 \mathrm{ml} \mathrm{min}^{-1}$ from 10 to $90 \%$ solvent B (acetonitrile) in solvent A (1,5\% o-phosphoric acid in water). Sinapate esters were photometrically detected at $330 \mathrm{~nm}$ and quantified by external standardization with authentic compounds. Sinapic acid and the other minor sinapate esters were identified by their for sinapic acid specific absorption maxima at $240 \mathrm{~nm}$ and $330 \mathrm{~nm}$. Their total content was calculated as $\mathrm{mg} / \mathrm{g}$ sinapate and their sum is given as 'other sinapate esters'. Total sinapate and sinapate ester content was calculated as sinapate equivalents ( $\mathrm{mg} / \mathrm{g}$ sinapate). Oil, protein, and glucosinolates were determined in whole seed by near-infrared reflectance spectroscopy (NIRS).

\section{Statistical analysis}

Analysis of variance was performed by the Plant Breeding Statistical Program (PLABSTAT), Version 2N (Utz 1997) using the following model: $Y_{i j k}=\mu+g_{i}+e_{j}+r_{j k}+g e_{i j}$ $+\varepsilon_{i j k}$ with $Y_{i j k}=$ observation of genotype $\mathrm{i}$ in environment $j$ in replication $k, \mu=$ general mean, $g_{i}=$ effect of genotype $i, e_{j}=$ effect of environment $j, r_{j k}=$ effect of replication $k$ in the environment $j, g_{\mathrm{e} i j}=$ genotype $\mathrm{x}$ environment interaction of genotype $i$ with environment $j, \varepsilon_{i j k}=$ residual error of genotype $i$ in environment $j$ in replication $k$. All factors were considered as random. Broad sense heritability $\left(h^{2}\right)$ for mean values over environments was calculated using PLABSTAT. 


\section{RESULTS}

The three doubled haploid populations showed a significant variation for the total sinapate ester ('total-SE') content (Tab. 1-3), which ranged from 1.3 fold (populations II and III) to 1.9-fold (population I). In population I the largest variation for total SE content was found, which ranged from 5.30 to $9.93 \mathrm{mg}$ sinapate per gram seed. This population also showed the largest variation for sinapoylglucose, sinapine and for sum of the other SE ('other SE'). In all three populations sinapine showed to be the predominant sinapate ester compound. Calculated on the basis of sinapate, the mean relative sinapine contents ranged from 58\% (Pop III) over 61\% (Pop I) to 72\% (Pop II) of the total SE content. The mean sinapoylglucose content contributed between 17\% (Pop II) and 20\% (Pop I+III) to the total SE content. The other SE content accounted for $10 \%$ in population II over $18 \%$ in population I to $22 \%$ in population III of the total SE content (Tab. 1-3).

For all three populations the analysis of variance showed highly significant effects for the genotype, the environment and the genoytpe $x$ environment (GXE) interactions (Tab. 13). For populations I and III the variance components showed for all traits a predominant effect of the genotype in comparison to the GxE interaction effect. The opposite was observed for population II. Here the GxE variance components were much bigger in comparison to the genotypic effects. In general, the experimental error varied with the constituent, but was high for total SE in all three populations. Accordingly, high heritabilities for all traits were obtained in population I and III, whereas only medium to low heritabilities were found in Pop II. This result compares favourably to the heritabilities obtained for oil content, which ranged from 0.66 (Pop III) to 0.89 (Pop I and II). 
Tab. 1: Variation $(\mathrm{mg} / \mathrm{g})$, components of variance and heritability for the content of sinapate esters of 142 doubled haploid lines from the cross $\mathrm{DH}$ Mansholts $\times \mathrm{DH}$ Samourai (Population I)

\begin{tabular}{|c|c|c|c|c|}
\hline & Sinapoylglucose & Sinapine & Other SE ${ }^{1}$ & Total-SE $^{1}$ \\
\hline \multicolumn{5}{|c|}{ Variation } \\
\hline Min & 0.93 & 5.19 & 0.47 & 5.30 \\
\hline Max & 5.30 & 9.25 & 2.39 & 9.93 \\
\hline Mean & 2.56 & 6.76 & 1.37 & 7.49 \\
\hline \multicolumn{5}{|c|}{ Components of variance } \\
\hline $\mathrm{G}$ & $0.9507^{\star *}$ & $0.4405^{\star *}$ & $0.1068^{\star \star}$ & $0.9411^{\star \star}$ \\
\hline$E$ & $0.1162^{\star \star}$ & $0.1606^{\star \star}$ & $0.0082^{\star *}$ & $0.0654^{\star \star}$ \\
\hline GxE & 0.1550 ** & $0.2434^{\star *}$ & $0.0571^{* *}$ & $0.2085^{\star *}$ \\
\hline error & 0.3081 & 0.3940 & 0.1190 & 0.6938 \\
\hline$h^{2}$ & 0.93 & 0.80 & 0.78 & 0.87 \\
\hline
\end{tabular}

${ }^{1}$ calculated as sinapate, $\mathrm{G}=$ genotype, $\mathrm{E}=$ Environment, $\mathrm{G} \times \mathrm{E}=\mathrm{G} \times$ Environment interactions,

$\mathrm{h}^{2}=$ heritability, ${ }^{\star \star} \mathrm{p}=0.01$ (F-test of MS in ANOVA)

Tab. 2: Variation $(\mathrm{mg} / \mathrm{g})$, components of variance and heritability for the content of sinapate esters of 49 doubled haploid lines from the cross 'High oleic $x$ Low Linolenic' (Population II)

\begin{tabular}{|c|c|c|c|c|}
\hline & Sinapoylglucose & Sinapine & Other SE ${ }^{1}$ & Total-SE ${ }^{1}$ \\
\hline \multicolumn{5}{|c|}{ Variation } \\
\hline Min & 1.17 & 7.02 & 0.22 & 6.61 \\
\hline Max & 3.20 & 9.17 & 1.28 & 8.83 \\
\hline Mean & 2.28 & 8.09 & 0.79 & 7.66 \\
\hline \multicolumn{5}{|c|}{ Components of variance } \\
\hline $\mathrm{G}$ & $0.1230 * \star$ & $0.1358 * *$ & $0.0208^{\star \star}$ & $0.1216^{\star \star}$ \\
\hline$E$ & $0.0396^{\star \star}$ & $0.0604^{\star \star}$ & -0.0008 & $0.0834^{\star \star}$ \\
\hline GxE & $0.1337^{\star *}$ & $0.1553^{* *}$ & $0.0317^{\star *}$ & $0.1678^{* *}$ \\
\hline error & 0.0800 & 0.2526 & 0.0485 & 0.2171 \\
\hline$h^{2}$ & 0.70 & 0.63 & 0.57 & 0.60 \\
\hline
\end{tabular}

${ }^{1}$ calculated as sinapate, $\mathrm{G}=$ genotype, $\mathrm{E}=$ Environment, $\mathrm{G} \times \mathrm{E}=\mathrm{G} \times$ Environment interactions,

$\mathrm{h}^{2}=$ heritability, ${ }^{\star \star} \mathrm{p}=0.01$ (F-test of MS in ANOVA) 
Tab. 3: Variation, components of variance and heritability for the content of sinapate esters derived from a cross between Sv0565 and DH Samourai $(n=46)$ (Population III)

\begin{tabular}{|c|c|c|c|c|}
\hline & Sinapoylglucose & Sinapine & Other SE ${ }^{1}$ & Total-SE ${ }^{1}$ \\
\hline \multicolumn{5}{|c|}{ Variation } \\
\hline Min & 1.55 & 5.58 & 0.84 & 6.90 \\
\hline $\operatorname{Max}$ & 3.39 & 7.63 & 2.17 & 9.17 \\
\hline Mean & 2.76 & 6.72 & 1.72 & 7.89 \\
\hline \multicolumn{5}{|c|}{ Components of variance } \\
\hline G & $0.1166^{\star *}$ & $0.2290^{\star *}$ & $0.0592^{\star \star}$ & 0.1986 ** \\
\hline$E$ & $0.3858^{\star *}$ & $1.4004^{\star \star}$ & $0.2088^{\star \star}$ & $2.3382^{\star \star}$ \\
\hline GxE & $0.0492^{\star \star}$ & $0.1087^{\star \star}$ & $0.0145^{\star \star}$ & $0.0634^{* *}$ \\
\hline error & 0.0850 & 0.2663 & 0.0510 & 0.2227 \\
\hline$h^{2}$ & 0.83 & 0.79 & 0.86 & 0.82 \\
\hline
\end{tabular}

${ }^{1}$ calculated as sinapate, $\mathrm{G}=$ genotype, $\mathrm{E}=$ Environment, $\mathrm{GxE}=\mathrm{G} \times$ Environment interactions,

$\mathrm{h}^{2}=$ heritability, ${ }^{\star \star} \mathrm{p}=0.01$ (F-test of MS in ANOVA)

The coefficients of correlations among the different sinapate esters and the oil, protein and glucosinolate content for the three populations are shown in Table 4. The total SE content was highly significantly positively correlated with the contents of the individual SE constituents. Non-existing (Pop I) or low, but highly significant negative correlations (Pop II + III) were found between sinapine and sinapoylglucose. In all three populations the other SE were not significantly correlated to sinapine but were highly significantly positively correlated to sinapoylglucose. Except for population II and the other SE there was no significant correlation between the oil content and any of the individual constituents or the total SE content, although highly significant genotypic differences in oil content were found in each of the three populations (data not shown). Similar results were found for the correlations to protein content. No correlation between the glucosinolate content and the total SE were found in all three populations, although highly significant genotypic variation was found (data not shown). In population II and III a significant positive correlation between sinapine and glucosinolates was found, whereas only in population II a highly significant negative correlation between sinapoylglucose and glucosinolate content was found. Population II segregated for oleic acid, linoleic and linolenic acid (data not shown; fatty acid data determined by gaschromatography were provided by Dr. Antje Schierholt, University of Göttingen). Here, oleic acid (18:1) was highly significantly positive correlated with sinapine $\left(r=0.56^{\star *}\right)$ and highly significantly negative correlated with sinapoylglucose $\left(r=-0.55^{\star}\right)$. Opposite 
correlations were found for linoleic acid ( $r=-0.55^{\star \star}$ and $r=0.45^{\star *}$, respectively). No correlation was found to the other SE and total SE content. In contrast to this, linolenic acid was highly significantly positive correlated to the other SE $\left(r=0.60^{\star \star}\right)$ and to the total SE $\left(r=0.49^{\star \star}\right)$, but no significant correlations to $18: 1$ and $18: 2$ were found.

Tab. 4: Pearsons' Coefficients of correlation for sinapate esters (SE) and the oil, protein and glucosinolate (GSL) contents for the three different doubled haploid populations (Population I-III)

\begin{tabular}{|c|c|c|c|c|c|c|c|c|}
\hline & $\begin{array}{l}\text { Popu- } \\
\text { lation }\end{array}$ & Sinapine & $\begin{array}{l}\text { Sinap.- } \\
\text { glucose }\end{array}$ & Other SE & $\begin{array}{l}\text { Total- } \\
\text { SE }\end{array}$ & Oil & Protein & GSL \\
\hline \multirow[t]{2}{*}{$\begin{array}{l}\text { Sinapoyl.- } \\
\text { glucose }\end{array}$} & $\begin{array}{l}\text { I } \\
\text { II } \\
\text { III }\end{array}$ & $\begin{array}{l}0.13 \\
-0.37^{\star \star} \\
-0.30^{\star}\end{array}$ & & & & & & \\
\hline & I & 0.06 & $0.54^{\star \star}$ & & & & & \\
\hline \multirow[t]{2}{*}{ Other SE } & $\begin{array}{l}\text { II } \\
\text { III }\end{array}$ & $\begin{array}{c}0.17 \\
-0.29\end{array}$ & $\begin{array}{l}0.44^{\star \star} \\
0.85^{\star \star}\end{array}$ & & & & & \\
\hline & 1 & 0.59 ** & $0.82^{\star \star}$ & 0.69 ** & & & & \\
\hline \multirow[t]{2}{*}{ Total-SE } & $\begin{array}{l}\text { II } \\
\text { III }\end{array}$ & $\begin{array}{l}0.58^{\star \star} \\
0.45^{\star \star}\end{array}$ & $\begin{array}{l}0.47^{\star *} \\
0.67^{\star *}\end{array}$ & $\begin{array}{l}0.78^{\star \star} \\
0.69^{\star \star}\end{array}$ & & & & \\
\hline & 1 & -0.07 & -0.07 & 0.00 & -0.07 & & & \\
\hline Oil & $\begin{array}{l}\text { II } \\
\text { III }\end{array}$ & $\begin{array}{l}0.08 \\
0.22 \\
\end{array}$ & $\begin{array}{l}-0.16 \\
0.09 \\
\end{array}$ & $\begin{array}{l}-0.30^{*} \\
-0.15 \\
\end{array}$ & $\begin{array}{c}-0.16 \\
0.13 \\
\end{array}$ & & & \\
\hline \multirow[t]{2}{*}{ Protein } & $\begin{array}{l}\text { I } \\
\text { II } \\
\text { III }\end{array}$ & $\begin{array}{l}0.02 \\
0.06 \\
0.22\end{array}$ & $\begin{array}{c}0.03 \\
-0.15 \\
-0.36^{\star}\end{array}$ & $\begin{array}{l}0.02 \\
-0.21 \\
-0.15\end{array}$ & $\begin{array}{r}0.03 \\
-0.13 \\
-0.07\end{array}$ & $\begin{array}{l}-0.65^{\star \star} \\
-0.42^{\star \star} \\
-0.73^{\star \star}\end{array}$ & & \\
\hline & I & 0.13 & 0.09 & -0.09 & 0.08 & $-0.35^{\star}$ & $0.21^{*}$ & \\
\hline GSL & $\begin{array}{l}\text { II } \\
\text { III }\end{array}$ & $\begin{array}{l}0.30^{\star} \\
0.33^{\star}\end{array}$ & $\begin{array}{c}-0.18 \\
-0.53^{\text {** }}\end{array}$ & $\begin{array}{c}-0.14 \\
-0.49 \text { ** }\end{array}$ & $\begin{array}{c}0.06 \\
-0.17\end{array}$ & $\begin{array}{c}-0.10 \\
0.08\end{array}$ & $\begin{array}{l}0.21 \\
0.23\end{array}$ & \\
\hline
\end{tabular}

*, ** significant at $p<0.05$ and $p<0.01$, respectively 


\section{DISCUSSION}

The present study revealed a large variation and highly significant genotypic differences for the total sinapate ester content in three different winter rapeseed populations. The largest variation for total SE was found in population I, which varied from 5.3 to $9.9 \mathrm{mg}$ sinapate per $g$ seeds. Calculated on the basis of sinapine, this variation $(0.9-1.7 \%)$ is about the same as the one reported by Bouchereau et al. (1991) for seed samples from 202 different $B$. napus types $(0.8-1.5 \%$, winter and spring types, oil and forage types, B. napus var. rapifera Metzg.). Analysing 1361 samples of rapeseed breeding lines by NIRS using a calibration which was based on reference values for total SE content obtained from a less accurate photometric test (Velasco et al. 1998), Velasco and Möllers (1998) reported on a range of total SE content from 0.5 to $1.8 \%$. Zum Felde (2005) determined by using HPLC analytics a variation in total SE content ranging from $0.3 \%$ to $1.3 \%$ in a set of 549 genotypic diverse winter rapeseed samples. Although these results fit quite well to each other, in all three reports single seed samples were analysed and the material has not been analysed after repeated testing in the field (Bouchereau et al. 1991, Velasco and Möllers 1998) or the results could not be confirmed (Zum Felde 2005). In those cases where the results were not confirmed after field testing, the data are of limited value because the total SE content has been reported to be considerably influenced by environmental conditions (Bouchereau et al. 1991, Wang et al. 1998). This was also confirmed in the present study, in which highly significant effects of the environment and genotype $x$ environment interactions were found. Therefore, the mean values obtained from several environments in the present study represent a more reliable estimation of the true genotypic contents and variation. In population II the mean sinapine content accounted for $72 \%$ of the total sinapate content. This is quite similar to the $70 \%$ reported by Boucherau et al. (1991) and the 65\% reported by Zum Felde (2005). However, in population III mean sinapine accounted for only 58\% of the total sinapate content. It is likely that for some genotypes of the tested populations, the relative content of sinapine is even less, but that has not been analysed.

Population I consisted of doubled haploid lines derived from a cross between the old winter variety "Mansholts' Hamburger Raps" and the relatively modern French winter rapeseed cultivar Samourai. From both cultivars completely homozygous doubled lines have been produced before crossing them to each other (Uzunova et al. 1995). Within this study, it turned out that the parental line DH Mansholts' had very low contents of total SE. This was also confirmed in a second population of doubled haploid lines derived from the cross DH Mansholts' and the German winter rapeseed cultivar Express (Zum 
Felde 2005). Hence, DH Mansholts' and related lines appear to be valuable starting material for a breeding program on low sinapate ester content.

High heritabilities were found for individual sinapate esters and for total SE content in population I and III (Tab. 1 and 3). This compared favourably to the equally high heritabilities of the oil content in these populations. Only population II showed medium size heritabilities for sinapate esters (Tab. 2). Compared to population III, which showed similar variance components for the genotypic effect and an error of a similar size, the genotype $x$ environment (GxE) interactions were much larger. Population II has been tested in the same environments as population III, however only in one year (2000), which was different from population III (2001 and 2002). It may be that the large GxE interactions are specific for the tested material, although the heritability for oil content was with $h^{2}=0.89$ as high as for population I. Noticeably, population III showed an unexpected low heritability of $h^{2}=0.66$, which has been explained by adverse weather conditions and a relatively large experimental error (see Marwede et al. 2004). Interestingly, this affected the heritability for oil and protein content, but not for the contents of secondary compounds like sinapate esters and glucosinolates (data not shown). Analysing seeds of the same three doubled haploid populations for another relevant secondary compound, the tocopherols, Marwede et al. (2004) reported only low heritabilities for the total tocopherols content, ranging from 0.34 to 0.48 .

The correlations between total SE content and sinapine, sinapoylglucose and the other SE were all positive and of a medium to high size. This indicates that reductions in total SE can be achieved by selecting for low contents of either one of the different compounds. This also suggests that a genetic combination of these individual traits should result in genotypes with an even lower content of total SE. Similar and even closer correlations among the individual sinapate esters and the total SE content was found by Hüsken et al. (2005a,b), when analysing segregating transgenic T2-plants with a drastically reduced total SE content (up to $83 \%$ reduction). The correlations among the individual SE can be to some extend explained by having a look at the biochemical pathway of these compounds (Milkowski et al. 2004, and references therein). In members of the Brassicaceae, sinapate is produced via the phenylalanine/hydroxycinnamate pathway. The first commited enzyme in SE biosynthesis is a glucosyltransferase catalysing the formation of sinapoylglucose from sinapate and UDP-Glucose. Sinapoylglucose serves as energy-rich sinapoyl donor in transacylation reactions leading in seeds to the synthesis of sinapine (sinapoylcholine), catalysed by the enzyme sinapoylglucose:choline sinapoyltransferase. The additional yet 
unknown sinapate ester compounds in minor concentrations ('other SE') are most likely also formed via sinapoylglucose (Milkowski et al. 2004). At least in populations II and III the biosynthesis of sinapine is associated with a reduction in the concentration of the direct precursor sinapoylglucose (Tab. 4). In contrast to this, the contents of the minor other SE increases with increasing contents of sinapoylglucose. Analysing the above mentioned T2-plants Hüsken et al. (2005a,b) did not find any indication that other important agronomic traits, like oil, protein, fatty acid and glucosinolate content of the seeds are affected by decreasing sinapate ester accumulation. These results could be confirmed in the present study with conventional non-transgenic material, in which no significant correlation between total SE and oil, protein and glucosinolate content was found.

In conclusion, medium to high heritabilities for the individual sinapate esters as well as for the total SE indicate, that an effective selection for low sinapate ester genotypes should be possible with a comparatively low effort with respect to number of required test environments, provided the breeding material shows a sufficiently high genotypic variation. There is no evidence that a reduction of sinapate ester content coincides with a change in other relevant seed quality traits. The NIRS technology together with the calibration equations developed by Zum Felde (2005) represent an effective analytical tool, because it allows in a large number of samples the non-destructive, fast and sufficiently accurate determination of the sinapate ester content, simultaneously to the prediction of other relevant seed quality traits like oil and glucosinolate content and fatty acid composition (Velasco and Becker 1998, Velasco et al. 1999).

\section{ACKNOWLEDGEMENT}

The authors are grateful to Dr. Alfred Baumert (IPB Halle) for providing his HPLCprotocol for the analysis of sinapate and sinapate esters, for providing sinapoylglucose as standard and for providing a HPLC-chromatogram that allowed peak identification. We also thank Dr. W. Ecke and Dr. Kemal Gül for providing seeds of the population I, and Dr. Antje Schierholt for providing seeds of population II. The technical assistance of Nicole Ritgen-Homayounfar is acknowledged. Many thanks to Norddeutsche Pflanzenzucht Hans-Georg Lembke KG (NPZ), Hohenlieth, for carrying out field experiments. This work is part of the research project "NAPUS 2000-Healthy Food from Transgenic Rape Seeds" and the financial support provided by the Bundesministerium für Bildung und Forschung (BMBF) is gratefully acknowledged. 


\section{REFERENCES}

Bell, J.M., 1993: Factors affecting the nutritional value of canola meal. A review. Can. J. Anim. Sci. 73: 679-697.

Bouchereau, A., J. Hamelin, I. Lamour, M. Renard and F. Larher 1991: Distribution of sinapine and related compounds in seeds of Brassica and allied Genera. Phytochemistry 30: 1873-1881.

Campbell, L.D., B.O. Eggum and I. Jacobsen 1981: Biological value, amino acid availability and true metabolizable energy of low-glucosinolate rapeseed meal (canola) determined with rats and/or roosters. Nutrition Reports International 24: 791-797.

Ecke, W., M. Uzunova and K. Weißleder 1995: Mapping the genome of rapeseed (Brassica napus L.). II. Localization of genes controlling erucic acid synthesis and seed oil content. Theor. Appl. Genet. 91: 972-977.

Gül, K., 2002: QTL-Kartierung und Analyse von QTL x Stickstoff Interaktionen beim Winterraps (Brassica napus L.). Cuvillier Verlag Göttingen, ISBN 3-89873-446-3.

Hüsken, A., A. Baumert, C. Milkowski, H.C. Becker, D. Strack and C. Möllers 2005a: Resveratrol glucoside (Piceid) synthesis in seeds of transgenic oilseed rape (Brassica napus L.). Theor. Appl. Genet.: DOI 10.1007/s00122-005-0085-1

Hüsken, A., A. Baumert, D. Strack, H.C. Becker, C. Möllers and C. Milkowski 2005b: Reduction of sinapate ester content in transgenic oilseed rape (Brassica napus) by dsRNAi-based suppression of BnSGT1 gene expression. Mol. Breed, in press.

Ismail, F., M. Vaisey-Genser and B. Fyfe 1981: Bitterness and astringency of sinapine and its components. Journal of Food Science 46: 1241-1244.

Kerber, E. and G. Buchloh 1980: Der Sinapingehalt in Cruciferensamen. Angewandte Botanik 54: 47-54.

Kozlowska, H., M. Naczk, F. Shahidi and R. Zadernowski 1990: Phenolic acids and tannins in rapeseed and canola, pp. 193-210. In: Shahidi, F. (Ed.), Canola and Rapeseed. Production, Chemistry, Nutrition and Processing Technology. Van Nostrand Reinhold, New York.

Kräling, K., G. Röbbelen and W. Thies 1991: Genetic variation of the content of sinapoyl esters in seeds of rape, B. napus. Plant Breeding 106: 254-257.

Leckband, G., M. Frauen and W. Friedt 2002: NAPUS 2000. Rapeseed (Brassica napus) breeding for improved human nutrition. Food Research International 35: 273-278.

Matthäus, B. 1997: Antinutritive compounds in different oilseeds. Fett/Lipid 99: 170-174. 
Milkowski, C., A. Baumert and D. Strack 2000: Cloning and heterologous expression of a rape cDNA encoding UDP-glucose:sinapate glucosyltransferase. Planta 211: 883886.

Milkowski, C., A. Baumert, D. Schmidt, L. Nehlin and D. Strack 2004: Molecular regulation of sinapate ester metabolism in Brassica napus: expression of genes, properties of the encoded proteins and correlation of enzyme activities with metabolite accumulation. Plant J. 38: 80-92.

Naczk, M., A. Aramowicz, A. Sullivan and F. Shahidi 1998: Current research developments on polyphenolics of rapeseeds/canola: a review. Food Chemistry 62: 489-502.

Nair, R.B., R.W. Joy, J. Schnaider, E. Kurylo, X. Shi, R.S.S. Datla, W.A. Keller and G. Selvaraj 2000: Identification of a CYP84 family of cytochrome P450- dependent mono-oxygenase genes in Brassica napus and perturbation of their expression for engineering sinapine reduction in the seeds. Plant Physiol. 123: 1623-1634.

Rahman, M.H. 2001: Production of yellow-seeded Brassica napus through interspecific crosses. Plant Breeding 120: 463-472.

Raney, J.P., G.F.W. Rakow, R.K. Gugel and T.V. Olson 1999: Low linolenic acid, 'zero' aliphatic glucosinolate Brassica napus. 10th International Rapeseed Conference, Canberra, Australia. www.regional.org.au/au/gcirc/4/81.htm. Site last visited on september 26, 2005

Shahidi, F. and M. Naczk 1992: An overview of the phenolics of canola and rapeseed: Chemical, sensory and nutritional significance. J. Am. Oil Chem. Soc. 69: 917-924.

Sozulski, F. 1979: Organoleptic and nutritional effects of phenolic compounds on oilseed protein products: A review. JAOCS 56: 711-715.

Thies, W. 1991: Determination of the phytic acid and sinapic acid esters in seeds of rapeseed and selection of genotypes with reduced concentrations of these compounds. Fat. Sci. Technol. 93: 49-52.

Tkachuk, R. 1981: Oil and Protein Analysis of Whole Rapeseed Kernels by Near Infrared Reflectance Spectroscopy. J. Am. Oil Chem. Soc. 58: 819-822.

Utz, F. 1997: Plabstat, ein Computerprogramm für statistische Analysen von Pflanzenzüchtungsexperimenten. Universität Hohenheim.

Uzunova, M.I., W. Ecke, K. Weissleder and G. Röbbelen 1995: Mapping the genome of rapeseed (B. napus L.) I. Construction of an RFLP linkage map and localization of QTLs for seed glucosinolate content. Theor. Appl. Genet. 90: 194-204.

Velasco, L., B. Matthäus and C. Möllers 1998: Nondestructive Assessment of Sinapic 
Acid Esters in Brassica Species: I. Analysis by Near Infrared Reflectance Spectroscopy. Crop Sci. 38: 1645-1650.

Velasco, L. and C. Möllers 1998: Nondestructive assessment of sinapic acid esters in Brassica species: II. Evaluation of germplasm and identification of phenotypes with reduced levels. Crop Sci. 38: 1650-1654.

Velasco, L. and H.C. Becker 1998: Analysis of total glucosinolate content and individual glucosinolates in Brassica spp. by near-infrared reflectance spectroscopy. Plant Breed. 117: 97-102.

Velasco, L., C. Möllers and H.C. Becker 1999: Estimation of seed weight, oil content and fatty acid composition in intact single seeds of rapeseed (Brassica napus L.) by near infrared reflectance spectroscopy. Euphytica 106: 79-85.

Wang, S., B.D. Oomah, D.I. McGregor and R.K. Downey 1998: Genetic and seasonal variation in the sinapine content of seed from Brassica and Sinapis species. Can. J. Plant Sci. 78: 395-400.

Zum Felde, T. 2005: Genetic variation for sinapic acid ester content in winter rapeseed (Brassica napus L.) and development of NIRS calibration equations. Manuscript I of this thesis 


\section{Danksagung}

Die Jahre sind viel zu schnell vergangen! Zum Erfolg dieser Arbeit haben viele Menschen beigetragen, denen ich an dieser Stelle herzlich danke möchte.

Namentlich besonders erwähnen möchte ich Herrn Dr. Christian Möllers für sein Vertrauen, die vielen Anregungen und seine tatkräftige Unterstützung besonders in der Endphase dieser Arbeit.

Herrn Prof. Dr. Heiko Becker danke ich für die Überlassung des Themas. Frau Prof. Dr. Elke Pawelzik danke ich für die Übernahme des Korreferates.

Den Mitarbeitern des Institutes für Pflanzenbau und Pflanzenzüchtung danke ich recht herzlich für die nette Arbeitsatmosphäre, Hilfsbereitschaft und die gute Zusammenarbeit. Besonders erwähnen möchte ich hier Frau Nicole Ritgen-Homayounfar und Herrn Uwe Ammermann, ohne deren stets tatkräftige Hilfe bei den Feldversuchen und den Analysen im Labor ein Gelingen dieser Arbeit nicht möglich gewesen wäre.

Besonderen Dank gilt Herrn Dr. Alfred Baumert (Institut für Pflanzenbiochemie, Halle (Saale)) für die vielen HPLC-Analysen. Seine wertvollen Hinweise für die Arbeit im Labor haben wesentlich zum Erfolg dieser Arbeit beigetragen.

Dank gilt auch den Mitarbeitern der Firmen Norddeutsche Pflanzenzucht Hans-Georg Lembke KG, Hohenlieth, und Deutsche Saatveredelung, Lippstadt, für die Durchführung von Feldversuchen.

Am herzlichsten bedanken möchte ich mich jedoch bei meinen ehemaligen Kollegen Dr. Wolfgang Grüneberg, Dr. Nurtjahjo Dwi Sasongko („Joe“) und Prof. Dr. Jan Olejniczak (Institut für Pflanzengenetik, Posen (Polen), zeitweise als Gastwissenschaftler in Göttingen) für die uneingeschränkt ausgeübte Solidarität auch an schwierigen Tagen am Institut. Danke!

Diese Arbeit wurde durch das Bundesministerium für Bildung und Forschung (BMBF) im Rahmen des Forschungsprojektes „NAPUS 2000 - Gesunde Nahrungsmittel aus transgener Rapssaat“ gefördert, dem ich für die gewährte Unterstützung danke. 
Lebenslauf

Name:

Thomas zum Felde

Geburtsdatum:

18.09.1972

Geburtsort:

21035 Hamburg - Bergedorf

Familienstand:

ledig, keine Kinder

Schulbildung:

1979 - 1983 Grundschule Hamburg - Bergedorf

1983 - 1992 Gymnasium am Bornbrook, Hamburg

Universitätsstudium: $1993-1995$ Studium der Biologie,

Gesamthochschule - Universität - Kassel

1995 - 1999 Studium der Biologie,

Georg-August-Universität Göttingen

Fachrichtung: Vegetationskunde, Dipl. Biologe

Ab 2000 Promotionsstudium am Institut für Pflanzenbau und Pflanzenzüchtung der Georg-August-Universität Göttingen 